\title{
ANAIS DA I SEMANA MÉDICO- CIENTÍFICA DA UNIVERSIDADE DE ITAÚNA - I SEMCI - UIT
}

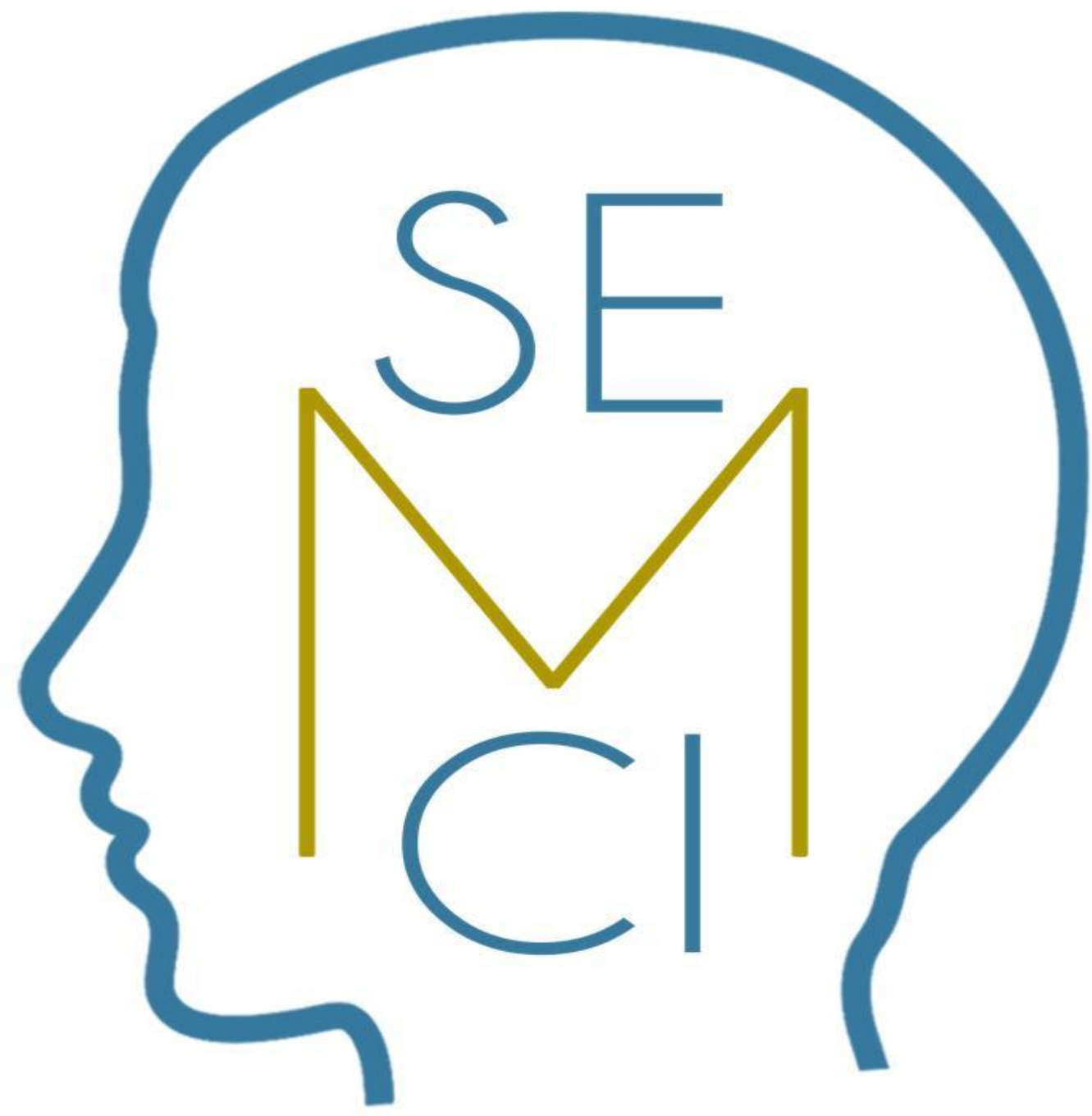

APOIO:
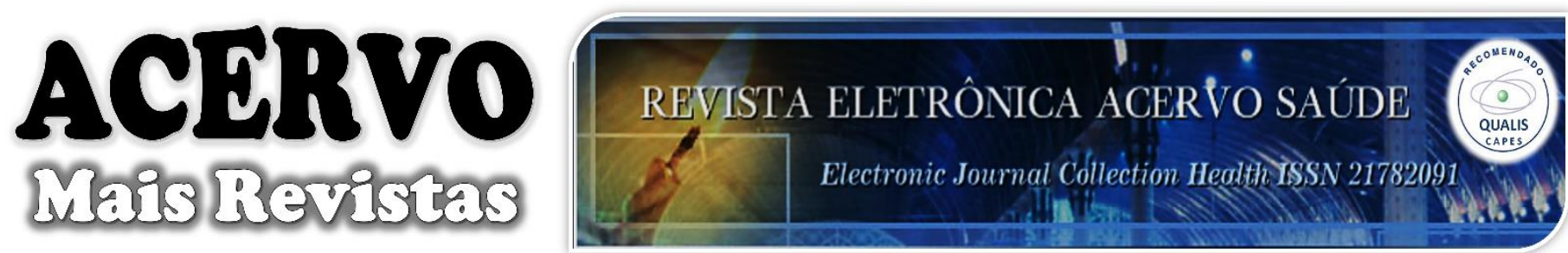

As publicações mais rápidas do país!

Indexada 0 Spentinodicos. Satindex Sumários.org

Google 


\section{FICHA TÉCNICA}

I SEMANA MÉDICO-CIENTÍFICA DA UNIVERSIDADE DE ITAÚNA - I SEMCI - UIT

Realizada entre os dias 04 a 13 de novembro de 2019 nas dependências da Universidade de Itaúna - UIT, Itaúna - MG, Brasil.

\section{APRESENTAÇÃO}

A SEMCI - UIT é um evento que reúne alunos e profissionais da área de Medicina e que visa, principalmente, fomentar a produção científica no meio acadêmico e contribuir na formação dos estudantes da região onde é realizada. Em sua primeira edição foi abordada a Clínica Médica como tema central e dentro dela, cinco eixos temáticos, sendo eles: Cardiologia, Endocrinologia, Infectologia, Neurologia e Pneumologia.

\section{Juliana Pigossi Neves Pires}

Presidente da Comissão Organizadora da I SEMCI - UIT 


\title{
INTEGRANTES DA COMISSÃO ORGANIZADORA
}

\section{Ana Cristina Nogueira Rodrigues Pestana ${ }^{1}$}

Orientadora

\author{
Juliana Pigossi Neves Pires ${ }^{2}$ \\ Presidente
}

\section{Larissa Caroline Rezende ${ }^{2}$ \\ Diretora Financeira}

\author{
Daniel Martucheli Sena ${ }^{2}$ \\ Igor Daniel Garcia Reis ${ }^{2}$ \\ João Vitor Flores Silveira ${ }^{2}$ \\ Maria Fernanda Silveira Dias ${ }^{2}$ \\ Monique Marianne Santana Santos ${ }^{2}$ \\ Diretores Científicos
}

Clara Menezes Gontijo²

Diretora de Propaganda

Alexandre Ferreira Lamounier ${ }^{2}$

Diretor Sociocultural

Tulio Esteves Tormin Botelho

Diretor de Patrocínios

1Docente Titular, Fundação Universidade de Itaúna - UIT, Itaúna-MG, Brasil

${ }^{2}$ Acadêmico de Medicina, Fundação Universidade de Itaúna - UIT, Itaúna-MG, Brasil 


\section{SUMÁRIO}

\section{CARDIOLOGIA}

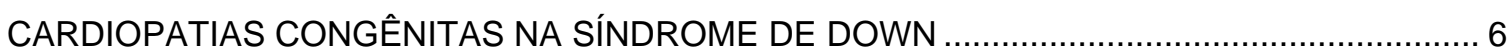

RELATO DE CASO: HIPERTENSÃO PULMONAR PRIMÁRIA …........................................... 8

ENDOCRINOLOGIA

ANÁLISE DA RELAÇÃO ENTRE OBESIDADE E SÍNDROME DOS OVÁRIOS POLICÍSTICOS 11 HIPOGLICEMIAS HIPERINSULINÊMICAS ENDÓGENAS DE DIFÍCIL MANEJO: RELATO DE CASO DE UM PROVÁVEL INSULINOMA

TERAPIA HORMONAL E COGNIÇÃO: UMA REVISÃO DE LITERATURA …............................... 15

TIREOIDITE SUBAGUDA RECORRENTE - UM RELATO DE CASO.

USO DE INIBIDORES DO CO-TRANSPORTADOR DE SÓDIO E GLICOSE 2 PARA O

TRATAMENTO DA DIABETES MELLITOS TIPO II.

A ESCOLHA TERAPÊUTICA ADEQUADA E O DIAGNÓSTICO PRECOCE DA LEISHMANIOSE TEGUMENTAR AMERICANA: UM RELATO DE CASO

A IMPORTÂNCIA DA PREVENÇÃO DA TRANSMISSÃO VERTICAL DO HIV: UMA REVISÃO DE LITERATURA.

CARACTERIZAÇÃO EPIDEMIOLÓGICA DA HANSENÍASE EM 2018 NO BRASIL .................... 26

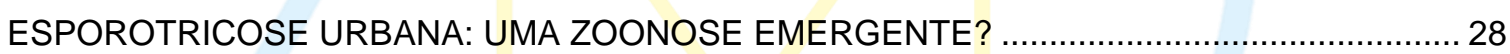

IMPACTOS DA HESITAÇÃO VACINAL NA EPIDEMIOLOGIA DO SARAMPO …......................... 30

SURTO DE SARAMPO: O CONTEXTO ATUAL E AS CAUSAS DE SUA REEMERGÊNCIA..... 32

NEUROLOGIA

APRESENTAÇÃO CLÍNICA E DIAGNÓSTICO DA DEMÊNCIA VASCULAR NA POPULAÇÃO IDOSA

DISTROFIA MUSCULAR DE CINTURAS DO TIPO 2B: RELATO DE CASO …........................... 37

ESQUIZENCEFALIA BILATERAL DE LÁBIOS ABERTOS: UM RELATO DE CASO .................... 39

MICROCEFALIA E DISTÚRBIOS PSICOMOTORES NA SÍNDROME DE AICARDI-GOUTIÈRES: UMA REVISÃO DE LITERATURA

SINTOMATOLOGIA E TRANSMISSÃO DA VARIANTE DA DOENÇA DE CREUTZFELDT JACOB

USO DE CÉLULAS-TRONCO PLURIPOTENTES INDUZIDAS NO TRATAMENTO DA DOENÇA DE PARKINSON.

USO DO CANABIDIOL NO TRATAMENTO DA DOENÇA DE PARKINSON.

PNEUMOLOGIA

E-CIGARETTES: AVANÇO OU RETROCESSO NA SAÚDE PÚBLICA?

O USO DO CIGARRO ELETRÔNICO: DO CONTROLE DO TABAGISMO AO RISCO DE SAÚD

TUBERSULOSE PLEURAL: A IMPORTÂNCIA DOS EXAMES COMPLEMENTARES PARA O DIAGNÓSTICO. 


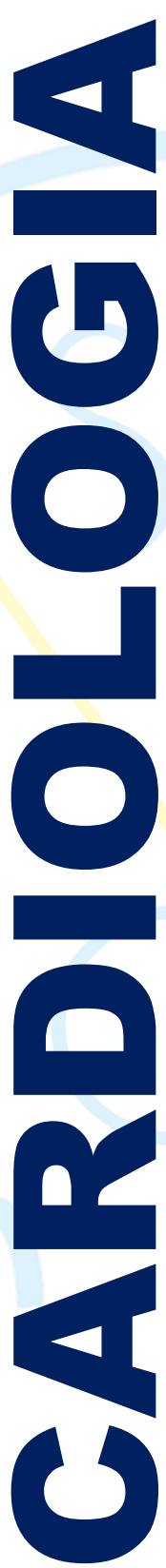




\title{
CARDIOPATIAS CONGÊNITAS NA SÍNDROME DE DOWN
}

\author{
Wellington de Jesus Ferreira Júnior ${ }^{1}$, Bruno Eduardo Freitas Gontijo ${ }^{1}$, Kalíli Danieli \\ Barra Ribeiro ${ }^{1}$, Wagner Ribeiro de Oliveira Junior ${ }^{1}$, Mauro Viana Morais ${ }^{2}$
}

\begin{abstract}
${ }^{1}$ Acadêmico de Medicina, Fundação Universidade de Itaúna - UIT, Itaúna - MG, Brasil 2Médico Clínico, Hospital Nossa Senhora da Conceição, Pará de Minas - MG, Brasil Endereço eletrônico: wellington2bh@gmail.com
\end{abstract}

\section{RESUMO}

A Síndrome de Down (SD) é caracterizada pela trissomia completa do cromossomo 21. No fenômeno da SD, destacam-se: déficits cognitivos, hipotonia muscular, malformações cardíacas, baixa estatura e dimorfismos faciais. As cardiopatias congênitas ocorrem em 40 a $60 \%$ dos portadores da síndrome, destacando-se na sua morbimortalidade, principalmente nos dois primeiros anos de vida. O estudo objetivou analisar a incidência de cardiopatias congênitas em portadores de Síndrome de Down, seus tipos mais prevalentes e a importância do diagnóstico precoce para o sucesso do tratamento. Para tal, foi realizada uma revisão da literatura nas bases de dados computadorizadas SciELO e PubMed, sendo utilizadas as palavras chaves: "Síndrome de Down", "Anormalidades Congênitas", "Cardiopatia", "Comunicação Interatrial" e "Tetralogia de Fallot". Foram selecionados 12 artigos em inglês e português para análise. Foi observado que entre os pacientes que apresentam a Síndrome de Down associada a cardiopatia congênita, a causa mais comum é a comunicação interatrial ostium secundum, com frequência de $51,8 \%$, seguida pelo defeito do septo atrioventricular, com $45,5 \%$ e pela persistência do canal arterial, com $34,8 \%$. A comunicação interventricular está presente em $27,7 \%$ dos casos, enquanto a tetralogia de Fallot representa $6,3 \%$ das cardiopatias. Outras cardiopatias totalizam $12,5 \%$. Além disso, a hipertensão pulmonar associa-se a $37,5 \%$ das cardiopatias. É importante salientar que boa parte dos pacientes apresentam mais de um defeito estrutural cardíaco concomitantemente. Apesar da alta prevalência de cardiopatia congênita, apenas $35,5 \%$ dos pacientes são encaminhados até os serviços de saúde e diagnosticados antes dos seis meses de idade. Esse dado é alarmante, vez que o diagnóstico precoce aliado ao tratamento cirúrgico efetivo são os principais responsáveis pela redução da morbimortalidade nessa população. Entre os métodos utilizados para a confirmação diagnóstica, destacam-se a ecocardiografia, eletrocardiografia, radiografia de tórax, cateterismo cardíaco e angiocardiografia. Quando diagnosticados precocemente e corrigidos cirurgicamente, os pacientes apresentam melhor sobrevida em relação aos que não realizam a correção cirúrgica. Dessa forma, conclui-se que o aumento da mortalidade nos dois primeiros anos de vida em portadores de Síndrome de Down está associado a alta prevalência de malformações cardíacas, relacionadas a trissomia do cromossomo 21. Sendo assim, todas as crianças com o diagnóstico da síndrome deveriam passar por uma avaliação cardíaca precoce e adequada, o que poderia diminuir a mortalidade e aumentar a sobrevida dessa população.

Palavras-chave: Síndrome de Down, Anormalidades congênitas, Cardiopatia, Comunicação interatrial, Tetralogia de Fallot. 


\section{REFERÊNCIAS}

CORONA-RIVERA, J. R, et al. Maternal risk factors for congenital heart defects in infants with Down syndrome from Western Mexico. American Journal of Medical Genetics Part A 179.9 (2019): 1857-1865

MOURATO, F. A, et al. Prevalência e perfil das cardiopatias congênitas e hipertensão pulmonar na síndrome de Down em serviço de cardiologia pediátrica. Revista Paulista de Pediatria 32.2 (2014): 159-163

NISLI, K. Prevalência de cardiopatias congênitas em portadores da síndrome de Down. Jornal de Pediatria 85.5 (2009): 377-378 


\title{
RELATO DE CASO: HIPERTENSÃO PULMONAR PRIMÁRIA
}

\author{
Bernardo Santos Resende1, Gustavo Santos Resende², Lucas de Barros Anastácio², \\ Ronaldo Torres de Freitas Filho ${ }^{1}$, Kevin Nata da Silva Santos ${ }^{3}$
}

\author{
${ }^{1}$ Médico, Hospital Felício Rocho, Belo Horizonte - MG, Brasil \\ ${ }^{2}$ Acadêmico de Medicina, Fundação Universidade de Itaúna - UIT, Itaúna - MG, Brasil \\ ${ }^{3}$ Médico, Prefeitura Municipal de Itaúna, Itaúna - MG, Brasil \\ Endereço eletrônico: bernardosr96@gmail.com
}

\section{RESUMO}

A hipertensão pulmonar primária (HPP) é uma doença rara, acometendo até dois casos em um milhão de pessoas. A patologia tem predileção pelo sexo feminino e tem elevada morbimortalidade, com sobrevida média de 2,8 anos após diagnóstico. Devido sua baixa incidência, estudos aprofundados acerca da HPP são escassos. Assim, o objetivo do presente trabalho foi apresentar um relato de caso em uma adulta de 40 anos. EAR, 40 anos, feminino. Em agosto de 2011, iniciou quadro de astenia e dispneia aos mínimos esforços, sendo motivada a procurar assistência médica. Foi solicitado radiografia de tórax, a qual revelou aumento do índice cardiotorácico e dilatação do tronco da artéria pulmonar. Foi, então, encaminhada ao cardiologista em 12/08/2011, que solicitou ecodopplercardiograma (ECO) e eletrocardiograma, evidenciando aumento importante das câmaras direitas (VD), hipertensão pulmonar importante (PSAP $=129 \mathrm{mmHg}$ ) e sinais de sobrecarga de VD. Posteriormente, realizou cateterismo cardíaco, que confirmou a hipertensão pulmonar (PSAP $=125 \mathrm{mmHg}$ ), e angiotomografia de tórax, a qual evidenciou dilatação do tronco arterial pulmonar $(4,1 \mathrm{~cm})$ e das artérias pulmonares direita $(3,3 \mathrm{~cm})$ e esquerda $(3,1 \mathrm{~cm})$. Demais exames laboratoriais e de imagem solicitados não evidenciaram alterações. Diagnosticado HPP, iniciou-se tratamento com uso de varfarina, espironolactona, furosemida, sildenafil e bosentana. Há um ano, a paciente aderiu-se a uma pesquisa com um novo fármaco, o riociguate, apresentando significativa melhora dos sintomas em repouso. Hoje, 8 anos após o diagnóstico, encontra-se estável hemodinamicamente, apresentando limitações em atividades rotineiras (NYHA III). Suspeição clínica e acesso a exames de imagem cardiovasculares são fundamentais para o diagnóstico precoce de HPP. A evolução no conhecimento de sua fisiopatologia permitiu o surgimento de importantes opções terapêuticas, com destaque ao riociguate. Esta medicação age como estimulante da guanilato ciclase solúvel, uma enzima do sistema cardiopulmonar e receptor do óxido nítrico, e tem apresentado resultados animadores em publicações internacionais. Apesar de rara, a HPP é desafiadora pois afeta, principalmente, mulheres jovens e previamente hígidas, apresentando uma evolução rápida com prognóstico sombrio. Sendo uma doença atualmente incurável, os conhecimentos para um diagnóstico precoce e instituição de terapia adequada são fundamentais para aumento da sobrevida e melhora da qualidade de vida dos pacientes. O ECO continua sendo uma das melhores ferramentas para rastreio e diagnóstico inicial da HPP, devendo ser sempre solicitado em caso de suspeita clínica. Novas drogas, como o riociguate, estão sendo testadas, e espera-se que apresentem avanços na terapêutica e prognóstico da HPP. 
Palavras-chave: Hipertensão pulmonar primária, Cardiopatia, Resistência vascular, Circulação pulmonar, Riociguate.

\section{REFERÊNCIAS}

$\mathrm{RICH}$, S, et al. Primary pulmonary hypertension: a national prospective study. Ann Intern Med 1987; 107:216-23

SANDOVAL, J, et al. Survival in primary pulmonary hypertension: validation of prognostic equation. Circulation 1994; 89; 1733-44

BARST, R. J, et al. Survival in primary pulmonary hypertension with long-term continuous intravenous prostacyclin. Ann Intern Med 1994; 121: 409-15 

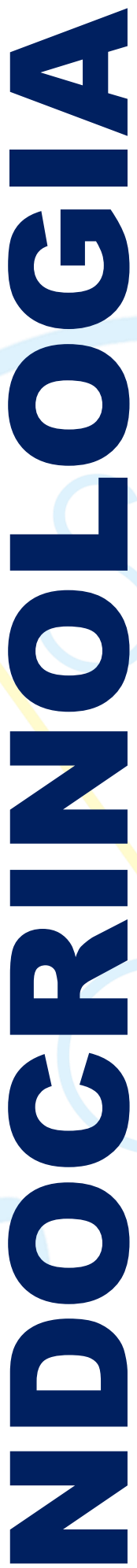

II 


\title{
ANÁLISE DA RELAÇÃo ENTRE OBESIDADE E SÍNDROME DOS OVÁRIOS POLICÍSTICOS
}

\author{
Isaias Jonatha Melo de Andrade", Lucas Vereza Loiola', Arthur Handerson Gomes Silva1, \\ lury Gualberto Fernandes ${ }^{2}$, Juliana Barros Mendes Rodrigues ${ }^{3}$
}

\begin{abstract}
${ }^{1}$ Acadêmico de Medicina, Universidade Federal de São João Del - Rei - UFSJ, Divinópolis - MG, Brasil

${ }^{2}$ Acadêmico de Medicina, Fundação Universidade de Itaúna - UIT, Itaúna - MG, Brasil

${ }^{3}$ Docente Titular, Fundação Universidade de Itaúna - UIT, Itaúna - MG, Brasil

Endereço eletrônico: isaias.fmed@gmail.com
\end{abstract}

\section{RESUMO}

Síndrome dos ovários policísticos (SOP) é uma desordem endócrina, caracterizada pela disfunção ovulatória e hiperandrogenismo. É apresentada por $5-10 \%$ das mulheres em idade fértil e comumente associada com disfunção reprodutiva e metabólica. A fisiopatologia da SOP é complexa, multifatorial e se relaciona com distúrbios metabólicos, que estão associados à obesidade e a outras comorbidades. Tendo em vista a relação com a obesidade e a resistência insulínica (RI), as intervenções se baseiam na mudança do estilo de vida. Na realização desse trabalho, objetivou-se analisar a relação entre obesidade, SOP e distúrbios metabólicos. Para isso foram selecionados artigos publicados no período de 2009 a 2019, nas bases de dados: Biblioteca Virtual em Saúde do Brasil, SciELO e PubMed, utilizando-se as palavras-chave: obesity, polycystic ovary syndrome, insulin resistance e metabolic syndrome. Nesse contexto, existem dois importantes aspectos na relação entre obesidade e SOP: o hiperandrogenismo e a RI com hiperinsulinemia compensatória, que aumenta progressivamente com a elevação do índice de massa corporal (IMC). O hiperandrogenismo eleva a expressão de genes envolvidos na lipogênese e contribui para o acúmulo de gordura na cavidade abdominal. Ainda, esse tecido adiposo causa um estado de inflamação constante, caracterizado por aumento das concentrações de adipocinas (leptina, interleucina-6, fator de necrose tumoral-alfa), que contribuem para a adipogênese, elevando a conversão de androstenodiona em testosterona. Ademais, tal acúmulo de gordura visceral leva ao aumento de glicogênese pelo fígado e a um aumento da liberação de insulina pelo pâncreas, juntamente da hiperinsulinemia compensatória gerada pela RI. A insulina aumenta a secreção de androgênios, tanto pela ação direta nas células tecais quanto pelo aumento do efeito de hormônio luteinizante (LH) nessas células. Outro fator envolvido nesse processo é a globulina ligante de hormônios sexuais (SHBG) que, com a ação da insulina em altas concentrações, está em menor quantidade, resultando em maiores níveis de androgênios livres. Além disso, mulheres com SOP que possuem maior quantidade de gordura abdominal e perfil lipídico alterado, apresentam risco maior para doença cardiovascular e para o desenvolvimento de diabetes tipo 2 . Tendo em vista a prevalência e as repercussões clínicas, é necessário o diagnóstico da SOP. No Brasil, utilizam-se os critérios de Rotterdam, baseados na presença de 2 dos 3 critérios: o hiperandrogenismo clínico e/ou laboratorial, oligo-amenorreia e critérios ultrassonográficos. Por fim, as mudanças a serem adotadas devem ser direcionadas 
ao controle da hiperinsulinemia, como a prática regular de exercícios físicos, reeducação alimentar e, caso necessário, terapia farmacológica.

Palavras-chave: Obesity, Polycystic ovary syndrome, Insulin resistance, Metabolic syndrome.

\section{REFERÊNCIAS}

COSTA, E. C. et al. Índices De Obesidade Central E Fatores De Risco Cardiovascular Na Síndrome Dos Ovários Policísticos. Arquivos Brasileiros de Cardiologia, v. 94, n. 5, p. 633-638, 2010

MOTTA, A. B. The Role of Obesity in the Development of Polycystic Ovary Syndrome Characteristics of PCOS Prenatal hyperandrogenism. Current Pharmaceuti Current Pharmaceutical Design cal Design p. 2482-2491, 2012

SPRITZER, P. M. Polycystic ovary syndrome: reviewing diagnosis and management of metabolic disturbances. Arquivos Brasileiros de Endocrinologia \& Metabologia, v. 58, n. 2 , p. $182-187,2014$ 


\title{
HIPOGLICEMIAS HIPERINSULINÊMICAS ENDÓGENAS DE DIFÍCIL MANEJO: RELATO DE CASO DE UM PROVÁVEL INSULINOMA
}

\author{
Gabriela Santos Pessoa Isidoro ${ }^{1}$, Carolina Rotatori Leal ${ }^{1}$, Isadora Chain Lima ${ }^{1}$, Stéfany \\ Henriques Pereira Silva1, Katiana Vinha de Sousa²
}

\begin{abstract}
${ }^{1}$ Acadêmico de Medicina, Fundação Universidade de Itaúna - UIT, Itaúna - MG, Brasil 2Médico Residente em Endocrinologia, Santa Casa de Misericórdia de Belo Horizonte, Belo Horizonte - MG, Brasil

Endereço eletrônico: gabriela19081994@hotmail.com
\end{abstract}

\section{RESUMO}

Os tumores secretores de insulina das ilhotas pancreáticas, os chamados insulinomas, apesar de raros (1 a 4/1.000.000), representam a principal causa de hipoglicemia hiperinsulinêmica endógena (HHE) em adultos (>90\%). Geralmente são benignos $(>85 \%)$, pequenos ( $>90 \%$ são $<2 \mathrm{~cm})$, solitários $(90 \%)$ e acometem indivíduos entre 40 e 50 anos. A ressecção cirúrgica é o tratamento de escolha, por ser a única alternativa de cura, sendo imprescindível, portanto, determinar previamente a localização da fonte de secreção patológica de insulina. Paciente M.B., 43 anos, sexo feminino, hipertensa, não diabética, portadora de transtorno depressivo e fibromialgia. Admitida na Santa Casa de Misericórdia de uma cidade do Estado de Minas Gerais, em 01/08/19, com relato de episódios frequentes de crises hipoglicêmicas graves nos últimos 3 anos, para extensão propedêutica. Exames laboratoriais prévios realizados na vigência de glicemia $<40 \mathrm{mg} / \mathrm{dL}$ demonstraram $\mathrm{HHE}$, com dosagens de insulina $(41,45 \mathrm{microUl} / \mathrm{mL}$ - VR: 3,0 a 25,0) e peptídeo C $(7,29 \mathrm{ng} / \mathrm{mL}$ - VR: 0,8 a 3,8) elevadas, cujos valores foram confirmados em novos exames basais e pelo teste do glucagon com resposta positiva, corroborando a hipótese de provável insulinoma. Em virtude da necessidade de internações recorrentes para controle glicêmico, já realizou investigação extensa através de exames de imagem, sem achado de tumor. Durante internação atual, iniciou-se tratamento clínico com infusão contínua endovenosa de solução hipertônica de glicose 13-15g/dia, Verapamil 80mg TID, Hidroclorotiazida 50mg MID e Octreotide 0,5mg/mL TID, porém sem resposta satisfatória. Foi optado, então, por aguardar em regime hospitalar a liberação judicial da tomografia por emissão de pósitrons com análogo de somatostatina marcado com Gálio-68 (PET/CT Ga68-DOTA). É importante enfatizar que, em pacientes aparentemente saudáveis, o insulinoma é a principal causa de HHE. A investigação consiste em contrapor o quadro clínico-laboratorial com outras possíveis causas de hiperinsulinemia, como hipoglicemia factícia, autoimune e por deficiências hormonais. Porém, a certeza de insulinoma só será possível após localização e estudo histopatológico do tumor, para excluir a raríssima possibilidade de nesidioblastose em adultos. Desta forma, o PET/CT possui maior acurácia para busca do nódulo pancreático produtor de insulina e, se captação presente, haverá possibilidade de ressecção cirúrgica e resolução do quadro. No entanto, em vista da necessidade de um exame de alto custo não fornecido pelo Sistema Único de Saúde (SUS), a extensão do tempo de internação torna-se obrigatória e indeterminada. A 
longa exposição ao ambiente hospitalar pode ser um fator dificultador, devido ao maior risco de infecções e à predisposição à exacerbação de transtornos de humor, contribuindo, assim, para descompensações hipoglicêmicas ainda mais frequentes.

Palavras-chave: Insulinoma, Hipoglicemia, Diagnóstico diferencial, Tomografia por emissão de pósitrons.

\section{REFERÊNCIAS}

ANTWI, K. et al. Localization of Hidden Insulinomas with 68Ga-DOTA-Exendin-4 PET/CT: A Pilot Study. Journal of Nuclear Medicine, Basel, Switzerland, v.56, n. 7, p. 1075-1078, mai. 2015

CRYER, P.E. et al. Evaluation and management of adult hypoglycemic disorders: An Endocrine Society Clinical Practice Guideline. The Journal of Clinical Endocrinology \& Metabolism, Boston, USA, v. 94, n. 3, p. 709-28. mar. 2009

OKABAYASHI, T. et al. Diagnosis and management of insulinoma. World Journal of Gastroenterology, Kochi, Japan, v. 19, n. 6, p. 829-37, fev. 2013 


\title{
TERAPIA HORMONAL E COGNIÇÃO: UMA REVISÃO DE LITERATURA
}

\author{
Sarah Fonseca e Silva¹, Marcone dos Santos Pereira ${ }^{1}$, Patrícia Alves Maia Guidine² \\ ${ }^{1}$ Acadêmico de Medicina, Fundação Universidade de Itaúna - UIT, Itaúna - MG, Brasil \\ 2Docente Titular, Fundação Universidade de Itaúna - UIT, Itaúna - MG, Brasil \\ Endereço eletrônico: sarahfonsecak3@hotmail.com
}

\section{RESUMO}

Fisiologicamente, a menopausa é definida como a interrupção dos ciclos menstrual. Nesta fase, há o declínio dos hormônios ovarianos estrogênio e progesterona, ditos substanciais às atividades cerebrais e, por isso, são utilizados como substrato de reposições terapêutica. Através desta revisão sistemática, objetiva-se enfatizar a relação entre a terapia de reposição hormonal (TRH) e seus benefícios cognitivos. Realizou-se uma busca na Biblioteca Virtual em Saúde, com os descritores "cognição, menopausa e reposição hormonal", sendo selecionados sete artigos científicos dos últimos seis anos. A priori, o climatério provoca alterações importantes no organismo feminino, como desequilíbrios da temperatura corporal, do humor, do sono e do intelecto, que poderiam ser minimizados com o tratamento hormonal. Todavia, somente $19,5 \%$ das mulheres utilizam ou já utilizaram essa terapêutica, por se tratar de uma questão científica polêmica. Nessa ótica, embora as pesquisas temáticas sejam relativamente recentes, nos últimos anos, vários estudos relataram a correlação entre os hormônios sexuais e a cognição. Tais trabalhos se basearam na atuação do estrogênio em sistemas neurotransmissores, como catecolaminérgico, serotoninérgico, dopaminérgico e gabaérgico e o poder de elevação da acetilcolina. Paralelamente, comprovou-se que a progesterona age no hipocampo e no prosencéfalo, indicando a relevância biológica da reposição nos processos de memória e de aprendizagem. Nesse âmbito, os experimentos fundamentaram que a $\mathrm{TRH}$ pode impedir os efeitos deletérios do envelhecimento e reduzir os riscos de demência, doença de Alzheimer e comprometimento cognitivo leve. De acordo com as investigações, pacientes que utilizaram os fármacos mantiveram o volume do córtex pré-frontal, área cerebral vinculada à memória, pensamento, planejamento e raciocínio. Além disso, a terapêutica é capaz de reduzir o acúmulo de placas betaamiloides, consideradas partes da fisiopatologia do Alzheimer. Em contrapartida, as pesquisas apontaram que os efeitos medicamentosos são mais eficientes no início da menopausa. Outrossim, as dosagens para cada paciente devem ser estritamente cautelosas, de modo que a progesterona, se administrada em valores maiores que os parâmetros estabelecidos, pode fomentar um efeito paradoxal, acometendo a memória. Portanto, a TRH traz benefícios ao controle cognitivo, desde que utilizada de maneira meticulosa e adaptada à paciente. Pesquisas sobre o tema são de extrema relevância, vez que o declínio das funções cerebrais é essencial ao prognóstico de doenças neurológicas. Diante disso, faz-se necessário o desenvolvimento de mais estudos na área que almejem abordagens clínicas e terapêuticas de sucesso. Assim, o processo se iniciará na farmacologia e progredirá em prol da saúde feminina. 
Palavras-chave: Cognição, Menopausa, Terapia de reposição hormonal.

\section{REFERÊNCIAS}

KANTARCI, K. et al. Brain structure and cognition 3 years after the end of an early menopausal hormone therapy trial. Neurology, v.90, n.16, p.1404-1412, 2018. Disponível em: https://n.neurology.org/node/161334.full. Acesso em: 29 set. 2019

MELO, C.S.B. et al. Cognitive decline and perimenopause: systematic review. Reprod Clim, v.32, n.2, p.132-137, 2017. Disponível em: https://www.sciencedirect.com/science/article/pii/S1413208716300711. Acesso em: 29 set. 2019

ROOZBEHI, A. et al. The impact of using different doses of progesterone on memory performance. Bratislava Medical Journal, v. 18, n.07, p.405-407, 2017. Disponível em:

http://www.elis.sk/download_file.php?product_id=5301\&session_id=2sbf7n8b3jmdu6 2eedvnir2jo4. Acesso em: $2 \overline{9}$ set. 2019 


\title{
TIREOIDITE SUBAGUDA RECORRENTE - UM RELATO DE CASO
}

\author{
Carolina Rotatori Leal ${ }^{1}$, Gabriela Santos Pessoa Isidoro", Luciana Caminha dos Reis ${ }^{1}$, \\ Stéfany Henriques Pereira Silva ${ }^{1}$, Katiana Vinha de Sousa ${ }^{2}$
}

\begin{abstract}
${ }^{1}$ Acadêmico de Medicina, Fundação Universidade de Itaúna - UIT, Itaúna - MG, Brasil 2Médico Residente em Endocrinologia, Santa Casa de Misericórdia de Belo Horizonte, Belo Horizonte - MG, Brasil

Endereço eletrônico: crotatori@hotmail.com
\end{abstract}

\section{RESUMO}

A tireoidite subaguda (TSA) é uma doença inflamatória autolimitada, rara, mais comum em mulheres. Trata-se de uma doença reativa que ocorre após 2 a 4 semanas de uma infecção viral, manifestando-se com dor cervical, febre, sintomas de hipertireoidismo, níveis suprimidos de TSH, elevação de T4 e alterações em ultrassonografia (US) cervical. Paciente J.S.M, 41 anos, sexo feminino, previamente hígida, internada por dor cervical intensa e febre, associada a um aumento difuso no lobo esquerdo da tireoide, linfonodomegalia cervical e faringomigdalite. Submetida a exames para avaliar função tireoidiana (TSH 0,08 Valor de Referência (VR): 0,34-5,60 e T4 LIVRE 2,04 VR: 0,6-1,2) e US cervical (lobo esquerdo aumentado, textura heterogênea e hipoecogênico, ausência nódulos. Fluxo aumentado ao doppler. Linfonodos reacionais em nível IV e VI) que confirmaram a hipótese diagnóstica de TSA. Iniciado tratamento com propanolol e anti-inflamatório não esteroidal (AINES). Após 2 dias sem melhora clínica, associou-se hidrocortisona endovenosa por 3 dias, seguida de prednisona $40 \mathrm{mg} / \mathrm{dia}$, com melhora sintomática e iniciado desmame gradual a cada 3 dias, com melhora laboratorial. Recebeu alta após 10 dias de internação, em uso de $20 \mathrm{mg} /$ dia do corticóide e propanolol $40 \mathrm{mg} / \mathrm{dia}$, com orientações para continuar redução da corticoterapia. Após 10 dias, procurou pronto-atendimento queixando-se de dor cervical difusa, pior à esquerda, com irradiação para ouvido esquerdo, iniciados há 5 dias, sendo transferida ao hospital para acompanhamento. Foram realizados novos exames, evidenciando eutireoidismo, e US cervical mantendo sinais de tireoidite. Reiniciada corticoterapia com dose otimizada de prednisona $40 \mathrm{mg} /$ dia com alívio sintomático rápido. Recebeu alta hospitalar assintomática, com orientações de reduzir a dose do corticoide a cada 7 dias e encaminhamento para acompanhamento ambulatorial da função tireoidiana. $O$ tratamento da TSA é baseado em estudos observacionais, direcionado para alívio da dor e dos sintomas, sendo comum o uso de AINES, corticoides e betabloqueadores. A recorrência da TSA com o uso da prednisona é em média 15\% e ocorre principalmente quando a dose chega em $10 \mathrm{mg}$, sendo recomendado 6 dias de intervalo entre as reduções. Comumente, esses casos evoluem com retorno do eutireoidismo, sendo o hipertireoidismo e hipotireoidismo transitórios. Aproximadamente 5-15\% dos pacientes evoluem com hipotireoidismo permanente. É importante respeitar o tempo de redução da dose de corticoide, para diminuir as chances de recidiva, apesar do mecanismo responsável não ser bem definido. O acompanhamento ambulatorial desses pacientes também se 
faz necessário, além de estudos voltados para uma alternativa farmacológica mais segura, para diminuir a sua recorrência.

Palavras-chave: Thyroiditis, Subacute, Recorrence, Prednisone.

\section{REFERÊNCIAS}

ARAO, T., et al. Prednisolone Dosing Regimen for Treatment of Subacute Thyroiditis. Open Journal of Endocrine and Metabolic Diseases, Moji, Japan, v.37, n.2, p 103-110, may. 2014

ENGKAKUL, P. et al. Quervain thyroiditis in a young boy following hand-foot-mouth disease. European Journal of Pedeatrics, Bangkok, Thailand, v.170, n.4, p 2010, oct. 2010

STASIAK, M. et al. The Risk of Recurrence of Subacute Thyroiditis Is HLA-Dependent. International. Journal of Molecular Sciences, Lodz, Poland, v.20, n.5, p.1089, mar 


\title{
USO DE INIBIDORES DO CO-TRANSPORTADOR DE SÓDIO E GLICOSE 2 PARA O TRATAMENTO DA DIABETES MELLITOS TIPO II
}

\author{
Geraldo Morais Rezende Netoํ, Emerson Alves da Silva Junior', Lara Amanda Silva \\ Amaral $^{1}$, Mariana Silva Amaral ${ }^{1}$, Ana Luiza Gontijo Freitas ${ }^{2}$
}

\begin{abstract}
${ }^{1}$ Acadêmico de Medicina, Fundação Universidade de Itaúna - UIT, Itaúna - MG, Brasil ${ }^{2}$ Médica Endocrinologista, Itaúna - MG, Brasil

Endereço eletrônico: moraisnetto885@gmail.com
\end{abstract}

\section{RESUMO}

Diabetes Mellitus (DM) é uma das doenças crônicas mais comuns no mundo. No Brasil, ela foi responsável por $11 \%$ dos óbitos registrados em 2017. A DM consiste em uma desregulação metabólica que resulta em um quadro de hiperglicemia constante, o que é tóxico para os tecidos do corpo. Existem vários tipos, como a Tipo $1 \mathrm{~A}$, Tipo 1B, Tipo 2 e gestacional. A DM Tipo 2 (DM2) é uma doença multifatorial com hiperglicemia perpetuante concomitantemente com a hiperglucagonemia, resistência dos tecidos periféricos à ação da insulina, aumento da produção hepática de glicose, aumento da absorção renal de glicose, graus variados de deficiência na síntese e secreção de insulina pelas células beta pancreáticas, aumento da lipólise e, consequentemente, aumento de ácidos graxos livres circulantes. Novos medicamentos da classe inibidores do co-transportador de Sódio e Glicose 2 (ISGLT2) estão sendo utilizados com eficácia no tratamento da DM2 e estudos, alguns em andamento, visam mostrar evidências e melhorias desses. O presente estudo tratase de uma revisão bibliográfica da eficácia dos ISGTL2 e seus efeitos adversos em textos publicados a partir de 2016 pesquisados no MEDLINE, PubMed e teses, utilizando as palavras-chave "Diabetes Mellitus", "inibidor SGTL-2" e "tratamento". O tratamento da DM2 consiste em associações entre intervenções terapêuticas e fármacos. Porém, os fármacos que são normalmente utilizados, como por exemplo a Metformina, primeira escolha em monoterapia e/ou em associação, possuem diversos efeitos colaterais, como náuseas, fadiga, diarreia e dor abdominal. Já as sulfoniluréias, utilizadas frequentemente em associação com a Metformina, podem causar hipoglicemia, sobretudo em idosos. Desse modo, estão sendo estudadas novas formulações que sejam mais efetivas e de menor poder ofensivo ao usuário. Assim, de acordo com os artigos analisados, o ISGLT2 teve como principais resultados: a redução significativa dos níveis glicêmicos, dos níveis de ácido úrico, da incidência de doenças cardiovasculares, do peso corporal, da pressão arterial, dos triglicérides, da albuminúria, da chance de ocorrência de hiperuricemia, além do aumento dos níveis de colesterol High Density Lipoproteins (HDL). Entretanto, alguns efeitos colaterais e riscos foram observados, como cetoacidose euglicêmica, candidíase vaginal, entre outros. Logo, é notória a importância do avanço de pesquisas dos tratamentos que atuem de forma diferente dos utilizados normalmente, a fim de buscar novos resultados. Percebeu-se que os ISGTL2 são utilizados e apresentam melhores resultados para a DM2, mas estudos prolongados ainda são necessários para evidenciar segurança, eficácia e efeitos colaterais a médio e longo prazo. 
Palavras-chave: Diabetes Mellitus, Tratamento, Diabetes Mellitus Tipo 2, Glicemia.

\section{REFERÊNCIAS}

FREITAS, A. L. G. Tratamento do Diabetes Mellitus tipo 2 por meio de inibidores do co-transportador sódio-glicose 2: 0 que diz a literatura?. 2018. 29 p. Monografia (Curso de Pós-Graduação Latosensu em Endocrinologia) - Faculdade IPEMED De Ciências Médicas, Belo Horizonte, 2018

HEERSPINK, H. J. L. et al. Dapagliflozin reduces albuminuria in patients with diabetes and hypertension receiving renin-angiotensin blockers. Diabetes, Obesity and Metabolism, Leicester, UK, v. 18, p. 590-597, 18 jun. 2016

ZACCARDI, F. et al. Efficacy and safety of sodium-glucose co-transporter-2 inhibitors in type 2 diabetes mellitus: systematic review and network meta-analysis. Diabetes, Obesity and Metabolism, Leicester, UK, p. 783-794, 18 ago. 2016 


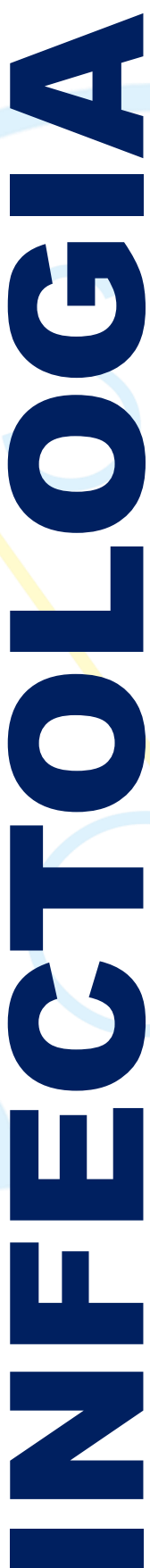




\title{
A ESCOLHA TERAPÊUTICA ADEQUADA E O DIAGNÓSTICO PRECOCE DA LEISHMANIOSE TEGUMENTAR AMERICANA: UM RELATO DE CASO
}

\author{
Caroline Mendonça Arruda ${ }^{1}$, José Abrantes Pêgo Neto ${ }^{1}$, Thaís Andrade de Souza², \\ Heitor Felipe Magalhães Menezes ${ }^{3}$
}

\begin{abstract}
${ }^{1}$ Acadêmico de Medicina, Fundação Universidade de Itaúna - UIT, Itaúna - MG, Brasil 2Médica Preceptora do Internato em Saúde Coletiva, Faculdade de Ecologia e Saúde Humana - FASEH, Vespasiano - MG, Brasil

${ }^{3}$ Médico, Estratégia de Saúde da Família, Itatiaiuçu - MG, Brasil

Endereço eletrônico: carolmendonca94@hotmail.com
\end{abstract}

\section{RESUMO}

A leishmaniose é uma antropozoonose causada pelo protozoário do gênero Leishmania. Possui amplo espectro de manifestações clínicas, variando de uma lesão cutânea de aspecto pápulo-vesiculoso até acometimento sistêmico grave. Pode ser do tipo tegumentar, mucosa ou visceral. Abordaremos a leishmaniose tegumentar americana (LTA), devido ao aumento de sua incidência no Brasil, mas também pela morbimortalidade da doença. C.M.M., 74 anos, sexo feminino, hipertensa, diabética, em uso de varfarina sódica; apresentou lesão papulosa eritemato infiltrada não pruriginosa em braço esquerdo em maio de 2018. Questionado como diagnóstico diferencial a possibilidade de linfoma ou de carcinoma de células escamosas, foi realizada em 29/08/18 biópsia diagnóstica, que teve como conclusão "dermatite crônica compatível com leishmaniose cutânea", com presença de estruturas intracelulares sugestivas de formas amastigotas de Leishmania sp. Foi iniciado tratamento com antimoniato de meglumina intralesional (Glucantine), $5 \mathrm{ml}$, com duração total de dez sessões e aproximadamente seis meses. A cada sessão eram realizados eletrocardiogramas e coagulogramas para avaliação dos efeitos colaterais sistêmicos do medicamento, sendo evidenciado descontrole dos valores da razão normalizada internacional (RNI) durante o tempo de tratamento. Ao fim das dez sessões, a paciente apresentou involução da lesão, porém desenvolveu arritmias sintomáticas e diminuição da fração de ejeção do ventrículo esquerdo ao ecodopplercardiograma. Após investigação mais detalhada, descartou-se evolução para a forma visceral da Leishmaniose. A LTA possui algumas opções terapêuticas de acordo com o perfil do paciente, sendo o antimoniato de meglumina e a anfotericina $\mathrm{B}$ as principais disponíveis no Brasil. A maioria das medicações disponíveis para o tratamento possui como efeito colateral, nefrotoxicidade e cardiotoxicidade. $\mathrm{O}$ diagnóstico e o tratamento precoce são importantes para a saúde coletiva, devido à possibilidade de interrupção do ciclo da leishmaniose e da redução das chances de disseminação sistêmica da doença, por isso, sendo necessário a investigação da existência de outros órgãos afetados pelo protozoário. A escolha correta do tratamento da LTA é fundamental para a redução dos possíveis efeitos colaterais. $\mathrm{Na}$ paciente do relato de caso, verificou-se que houve repercussões cardiológicas ao fim do esquema terapêutico, deixando-se questionado se a medicação escolhida foi a que 
melhor se adequava a paciente. Infere-se ainda que a descoberta da doença em sua fase inicial está relacionada a menor chance de evolução para a forma visceral. Fazse necessário que as medidas de diagnóstico e prevenção da Leishmaniose também sejam mais eficazes, para conter o aumento da incidência da doença e a diminuição da morbimortalidade.

Palavras-chave: Leishmaniose, Leishmaniose cutânea, Arritmias cardíacas, Cardiotoxicidade.

\section{REFERÊNCIAS}

BRASIL. Ministério da Saúde. Manual de vigilância da leishmaniose tegumentar. Brasília, 2017

RODRIGUES, A.M. et al. Fatores associados ao insucesso do tratamento da leishmaniose cutânea com antimoniato de meglumina. Revista da Sociedade Brasileira de Medicina Tropical, v.39, n.2, p. 139-145, mar.-abr. 2006

GONTIJO, B.; CARVALHO, M. L. R. Leishmaniose tegumentar americana. Revista da Sociedade Brasileira de Medicina Tropical, v.36, n.1, p. 71-80, jan.-fev. 2003 


\title{
A IMPORTÂNCIA dA PREVENÇÃO DA TRANSMISSÃO VERTICAL DO HIV: UMA REVISÃO DE LITERATURA
}

\author{
Marcone dos Santos Pereira ${ }^{1}$, Sarah Fonseca e Silva ${ }^{1}$, Miriam Nogueira Barbosa ${ }^{2}$
}

\author{
${ }^{1}$ Acadêmico de Medicina, Fundação Universidade de Itaúna - UIT, Itaúna - MG, Brasil \\ 2Docente Titular, Fundação Universidade de Itaúna - UIT, Itaúna - MG, Brasil \\ Endereço eletrônico: marconeesantos@gmail.com
}

\section{RESUMO}

Atualmente a transmissão vertical do vírus da imunodeficiência humana (TV-HIV) tem sido responsável pelos casos de AIDS no Brasil em 93,2\% das crianças com até 13 anos de idade. Esse dado alerta para a importância de mais estudos sobre a prevenção da TV-HIV em gestantes, pois existem intervenções efetivas para esse grave problema de saúde pública. Nesse contexto, este trabalho objetiva enfatizar a importância das diretrizes para a redução da TV-HIV. Para tanto, realizou-se uma revisão literária de artigos e protocolos oficiais sobre o tema, nas plataformas SciELO e BVS, com os descritores: "prevenção de transmissão vertical HIV". Dos materiais encontrados, dez foram selecionados para análise. Verificou-se que em gestações planejadas, com intervenções realizadas adequadamente durante o pré-natal, o parto e amamentação, o risco de transmissão vertical do HIV é reduzido a menos de $2 \%$. Entretanto, sem o adequado planejamento e seguimento, está estabelecido que esse risco é de 15 a 45\%. Os momentos da transmissão perinatal do HIV são intra-útero, com 20 a 25\% dos casos; peri-parto, com 60 a 75\% e pós-natal, com 14 a 29\%. A recomendação é que o teste anti-HIV seja realizado na primeira consulta do pré-natal, no início do terceiro trimestre e no momento do parto. Apesar das evidências de que o uso de antirretrovirais (ARV) seja seguro e efetivo para a redução da TV-HIV, estudos demonstram que cerca de $70 \%$ das grávidas em tratamento e sem exposição prévia aos ARV não atingem supressão viral próxima ao parto, o que impacta no risco de transmissão. A principal causa dessa não supressão viral nesse grupo é a adesão insuficiente. Nesse sentido, para o sucesso das políticas atuais de tratamento e acompanhamento de gestantes infectadas pelo HIV durante o pré-natal e após o parto, a equipe de saúde deve estar atenta aos aspectos individuais e dinâmicos que afetam a adesão. É imprescindível que essas mulheres recebam informações sobre os benefícios da terapia antirretroviral e que lhes seja garantido espaço para discussão de dúvidas e eventuais temores sobre possíveis impactos negativos das medicações nos recém-nascidos. Portanto, como sugere a OMS, para atingir a meta de eliminação de novos casos entre crianças, as ações devem abranger um pacote de intervenções que inclui a prevenção nas mulheres soronegativas, planejamento reprodutivo, testagem precoce para o HIV no pré-natal e suporte para que gestantes HIV soropositivas tenham adesão ao tratamento retroviral e permaneçam em acompanhamento no sistema de saúde.

Palavras-chave: Transmissão vertical, HIV, Prevenção. 


\section{REFERÊNCIAS}

MINISTÉRIO DA SAÚDE. Secreta de Vigilância em Saúde, Departamento de Vigilância, Prevenção e Controle das Infecções Sexualmente Transmissíveis, do HIV/Aids e das Hepatites Virais. Boletim Epidemiológico HIV AIDS - Brasília. v.49, n.53. 2018. Disponível em: http://www.aids.gov.br/pt-br/pub/2018/boletimepidemiologico-hivaids-2018. Acesso em: 30 set. 2019

MINISTÉRIO DA SAÚDE. Secretaria de Vigilância em Saúde. Departamento de Doenças de Condições Crônicas e Infecções Sexualmente Transmissíveis. Protocolo Clínico e Diretrizes Terapêuticas para Prevenção da Transmissão Vertical do HIV, Sífilis e Hepatites Virais. - Brasília: Ministério da Saúde, 2019. Disponível em: http://www.aids.gov.br/pt-br/pub/2015/protocolo-clinico-e-diretrizes-terapeuticaspara-prevencao-da-transmissao-vertical-de-hiv. Acesso em: 28 set. 2019

WHO. World Health Organization. Guia consolidada sobre saúde sexual e reprodutiva e direitos das mulheres vivendo com HIV/AIDS. Traduzido por centro Latino-Americano de Perinatologia, Saúde da Mulher e Reprodutiva da Organização Pan-Americana da Saúde. Geneva: Organização Mundial Da Saúde, 2017. Disponível em: https://apps.who.int/iris/bitstream/handle/10665/254634/WHORHR-

17.03eng.pdf;jsessionid=1A4F62CBDDB8E91C718FB466CAC2457E ?sequence $=1 \mathrm{~A}$ cessado em 30 de Setembro de 2019 


\title{
CARACTERIZAÇÃo EPIDEMIOLÓGICA DA HANSENÍASE EM 2018 NO BRASIL
}

\author{
Ana Raquel Gonçalves Petersen ${ }^{1}$, Paula Figueiredo Vilela ${ }^{1}$, Stênio Pereira de \\ Carvalho Junior ${ }^{1}$, Betânia Maria Soares ${ }^{2}$
}

\begin{abstract}
${ }^{1}$ Acadêmico de Medicina, Fundação Universidade de Itaúna - UIT, Itaúna - MG, Brasil ${ }^{2}$ Docente Titular, Fundação Universidade de Itaúna - UIT, Itaúna - MG, Brasil Endereço eletrônico: anaraquelitauna@hotmail.com
\end{abstract}

\section{RESUMO}

Hanseníase é uma doença endêmica na sociedade mundial provocada pela Mycobacterium leprae, bactéria altamente infectocontagiosa, transmitida pelo contato próximo com pessoas não tratadas e infectadas pelo bacilo. Apresenta como características principais manchas brancas ou avermelhadas insensíveis ao tato e às variações de temperatura. Tendo em vista a discrepância do número de casos por região no Brasil em 2018, a caracterização epidemiológica da Hanseníase poderia elucidar quais fatores contribuem para sua persistência, bem como o que pode ser usados no combate à doença. Por isso, o presente trabalho tem como função analisar e discutir os aspectos epidemiológicos da prevalência e incidência da Hanseníase em 2018 no Brasil, por meio dos dados disponíveis pelo Ministério da Saúde na plataforma DATASUS. Primeiramente, foi realizada uma pesquisa sistemática com o tema "Persistência da Hanseníase" na plataforma DATASUS, para o levantamento e análise dos dados fornecidos pelo Ministério da Saúde. Em segundo plano, realizou-se a leitura integral de alguns artigos acadêmicos na plataforma BVS e foram comparados os dados contidos neles com aqueles disponibilizados pelo governo. Finalizado esse processo, ocorreu então a discussão dos resultados e a conclusão do assunto. Com base nos resultados obtidos, observou-se que, em 2018, a forma indeterminada da hanseníase diminuiu de forma discreta e, em contrapartida, as formas dimorfa e virchowiana sofreram aumento, demonstrando que o diagnóstico e a classificação das pessoas afetadas pela doença podem ter sofrido uma melhora. A possível relação entre imunização com a vacina BCG (Bacilo Calmette-Guérin) e número de casos novos revelou que, em regiões menos vacinadas, a prevalência da hanseníase foi maior, uma vez que pessoas imunizadas apresentaram melhor resistência à doença, deixando implícito uma alternativa para o seu controle. Ademais, não foi observado grande discrepância entre o contágio entre mulheres e homens, porem houve diferença considerável na faixa etária entre 35 e 64 anos. Diante dos fatos supracitados e considerando todos os dados levantados, conclui-se que a precisão diagnóstica aumentou e as regiões imunizadas apresentaram uma menor incidência de novos casos em 2018.

Palavras-chave: Hanseníase, Epidemiologia, Diagnóstico, Imunização, Brasil. 


\section{REFERÊNCIAS}

DEPARTAMENTO DE INFORMÁTICA DO SUS - DATASUS. Hanseníase - Brasil, 2018.

$<$ http://tabnet.datasus.gov.br/cgi/dhdat.exe?ETL_hanseniase/ETL_hantfbr18.def>.

Acesso em: 02 maio de 2019

HELIANA, M.; MONTEIRO, C.; SOCORRO, P.; et al. Fatores de risco em contatos intradomiciliares de pacientes com hanseníase utilizando variáveis clínicas, sociodemográficas e laboratoriais. Rev Pan-Amaz Saude, Ananindeua, v. 8, n. 2, p. 21-28, jun. 2017.

Disponível

em: $<$ http://scielo.iec.gov.br/scielo.php?script=sci_arttext\&pid=S217662232017000200021\&lng=pt\&nrm=iso>

MINISTÉRIO DA SAÚDE - SECRETARIA DE VIGILÂNCIA EM SAÚDE. Boletim Epidemiológico - Hanseníase. V.49, n.4, Brasília, 2018. Disponível em: <http://portalarquivos2.saude.gov.br/images/pdf/2018/janeiro/31/2018-004-

Hanseniase publicacao.pdf>. Acesso em 02 mai. 2019 


\title{
ESPOROTRICOSE URBANA: UMA ZOONOSE EMERGENTE?
}

\author{
Bruno Vítor Peixoto Militão', Lucas Domingos Ribeiro', Miriam Nogueira Barbosa²
}

${ }^{1}$ Acadêmico de Medicina, Fundação Universidade de Itaúna - UIT, Itaúna - MG, Brasil ${ }^{2}$ Docente Titular, Fundação Universidade de Itaúna - UIT, Itaúna - MG, Brasil Endereço eletrônico: bruno.militao@icloud.com

\section{RESUMO}

A esporotricose é uma infecção de inoculação traumática, causada por fungos do gênero Sporothrix, que geralmente acomete os tecidos cutâneo e subcutâneo e, excepcionalmente, ossos, sistema nervoso central, olhos, coração e pulmões. As espécies do gênero Sporothrix são amplamente encontradas na natureza, podendo ser isoladas a partir do solo e elementos de origem vegetal. Logo, a esporotricose é observada com maior frequência entre profissionais de áreas afins, como trabalhadores rurais e jardineiros, tendo caráter ocupacional. No entanto, no Brasil, a doença se estabeleceu como uma epidemia zoonótica, em que o gato foi identificado como principal agente transmissor da doença. Diante disso, relatamos caso de homem, 21 anos, que residia em área urbana nobre, em uma cidade do Estado de Minas Gerais, convivia com quatro gatos que não apresentavam lesões. Em maio de 2019, o paciente apresentou lesão inflamatória em terceiro quirodáctilo direito, sugestiva de paroníquia bacteriana, hiperêmica, com ulceração, dor e edema local, acompanhada de nodulações distais em membro superior direito. Foi realizada antibioticoterapia com cefalexina por 14 dias, com piora do quadro sintomático. Encaminhado ao serviço de dermatologia para solicitação de biópsia, foi constatada linfadenopatia em padrão de rosário, de caráter ascendente à lesão. Com quadro clínico sugestivo de esporotricose, foi iniciado tratamento empírico com itraconazol $200 \mathrm{mg} /$ dia. Houve, na primeira semana, intensa ulceração e descamação das lesões, seguida de regressão sintomática. O término do tratamento deu-se em três meses. Permanece assintomático um mês após o cessar da medicação. Diversas apresentações clínicas são descritas, porém as formas cutâneas localizada e cutânealinfática persistem como as apresentações mais corriqueiras. O diagnóstico da infecção pauta-se em: história clínica; exame físico - que permita a tipificação e eventualmente a presença de sinais patognomônicos ("rosário esporotricótico") - e no isolamento do fungo através de cultura. Porém, nem sempre o médico terá à disposição exames laboratoriais adequados devendo, pois, estar inteirado quanto às manifestações clínicas características para o reconhecimento e diagnóstico. Infere-se que o contato dos indivíduos com gatos no ambiente domiciliar tenha crescido nos últimos anos, o que contribuiria para o aumento da possibilidade de epidemias e infecção da população. O caso relatado corrobora a importância desse animal na transmissão da doença e a necessidade de controle da população felina. Reitera, também, a importância da observação e reconhecimento das manifestações clínicas clássicas. Além disso, fomenta medidas de educação coletiva e preparo dos profissionais de saúde para que estejam adequadamente preparados para orientar, fazer diagnóstico precoce e tratamento correto da doença.

Palavras-chave: Esporotricose, Zoonoses, Transmissão, Atenção à saúde. 


\section{REFERÊNCIAS}

SILVA, G. M. et al. Surto de esporotricose felina na região metropolitana do Recife. Brazilian Journal of Veterinary Research. Rio de Janeiro, v. 38, n. 9, p. 1767-1771, Set. 2018

SILVA, M. B. T. da, et al. Esporotricose urbana: epidemia negligenciada no Rio de Janeiro, Brasil. Cad. Saúde Pública, Rio de Janeiro, v. 28, n. 10, p. 1867-1880, Out. 2012

ZAITZ, C. et al. Compêndio de Micologia Médica. 2. ed. atual. Rio de Janeiro: Guanabara Koogan, 2010. 432 p 


\title{
IMPACTOS DA HESITAÇÃO VACINAL NA EPIDEMIOLOGIA DO SARAMPO
}

\author{
Maria Tereza Nogueira Fonseca e Souza1, Kamila Castro Oliveira Camargos ${ }^{1}$, \\ Marcela Rêda Guimarães ${ }^{1}$, Mariana Rodrigues de Oliveira Neves ${ }^{1}$, Cíntia Fontes \\ Alves $^{2}$
}

\begin{abstract}
${ }^{1}$ Acadêmico de Medicina, Fundação Universidade de Itaúna - UIT, Itaúna - MG, Brasil ${ }^{2}$ Docente Titular, Fundação Universidade de Itaúna - UIT, Itaúna - MG, Brasil Endereço eletrônico: mariaterezanogueirafs@gmailcom
\end{abstract}

\section{RESUMO}

O sarampo é uma infecção altamente contagiosa, causada pelo vírus Measles morbillivirus. A transmissão ocorre por vias aéreas e os principais sintomas são febres, tosse, coriza, congestão nasal e mal-estar. Em 3 a 5 dias, pode também surgir exantema abrangendo todo corpo. A profilaxia para o sarampo é a vacinação, que é disponibilizada pelo Sistema Único de Saúde (SUS). Em 1990, a cobertura vacinal contra o sarampo estava acima de $95 \%$, porém, a partir de 2016 , observou-se queda nas taxas de vacinação, com declínio de 10 a 20 pontos percentuais, levando a perda da certificação de erradicação do sarampo concedida ao Brasil em 2013 pela Organização Pan-Americana de Saúde (OPAS). O objetivo deste trabalho é realizar uma análise das campanhas de vacinação do sarampo para compreender o que levou ao surto dessa afecção em 2019, bem como discutir as implicações da hesitação vacinal na epidemiologia. Para tanto, realizou-se uma revisão bibliográfica, sobre hesitação vacinal e epidemia de sarampo nas bases de dados BvS e PubMed, além de análise de dados disponibilizados pelo DATASUS sobre abrangência da campanha de vacinação contra o sarampo e informes epidemiológicos do Ministério da Saúde. $\mathrm{O}$ aumento das notificações dessa virose teve início em 2013. No período de 2013 a 2015 foram registrados 1.310 casos de sarampo no Ceará e Pernambuco. Em 2017, a cobertura da vacinação no Brasil foi de $84,9 \%$ na primeira dose e de $71,5 \%$ na segunda, índice inferior à meta de $95 \%$ preconizada pelo Programa Nacional de Imunizações. Em 2018, nos estados Amazonas e Roraima, mais de 1500 casos foram notificados e, em janeiro de 2019, foram confirmados 4.776 casos no país. Diante desses números, uma importante hipótese para o declínio da vacinação é a hesitação vacinal, nomenclatura reconhecida pela Organização Mundial de Saúde (OMS) em 2012, dada a importância do fenômeno. Ainda não há muitas publicações sobre hesitação vacinal e epidemia de sarampo no Brasil, porém a hipótese já é considerada pela Fiocruz e por comunicados do Ministério da Saúde a respeito de notícias falsas contrárias a vacinação. O fenômeno já teve relevância reconhecida no surto de sarampo ocorrido em 2000 nos EUA, onde a desconfiança de parte da população acerca dos benefícios da vacinação contribuiu para o ressurgimento da virose. Dessa forma, questiona-se se o atual surto de sarampo no Brasil se relaciona com a hesitação vacinal.

Palavras-chave: Sarampo, Surto, Recusa de vacinação, Infecção, Cobertura vacinal. 


\section{REFERÊNCIAS}

MAJUMDER, M. S. et. al. Substandard Vaccination Compliance and the 2015 Measles Outbreak. JAMA, United States, v.169, n. 5, p.494-495, may. 2015. Disponível em: <https://jamanetwork.com/journals/jamapediatrics/fullarticle/2203906> Accesso em 04 Nov. 2019. DOI:10.1001/jamapediatrics.2015.0384

MINISTÉRIO DA SAÚDE. Situação do Sarampo no Brasil - 2019. Brasília, 2019. Disponível em: <https://portalarquivos2.saude.gov.br/images/pdf/2019/janeiro/28/Informe-Sarampon36-24jan19aed.pdf>

SATO, A. P. S. Qual a importância da hesitação vacinal na queda das coberturas vacinais no Brasil? Rev. Saúde Pública, São Paulo, v. 52, n.96, 2018. Disponível em: $<$ http://www.scielo.br/scielo.php?script=sci_arttext\&pid=S0034-

89102018000100601\&lng=en\&nrm=iso >. Accesso em 04 Nov. 2019. DOI: http://dx.doi.org/10.11606/s1518-8787.2018052001199 


\title{
SURTO DE SARAMPO: O CONTEXTO ATUAL E AS CAUSAS DE SUA REEMERGÊNCIA
}

\author{
Giovanna Luiza Medina Ferreira', Alice Fernandes Anselmo ${ }^{1}$, Bernardo Lepesqueur Corradi \\ Magalhães ${ }^{1}$, Fernanda Luiza Gomes de Abreu', Mariana Cachero Lino²
}

\begin{abstract}
${ }^{1}$ Acadêmico de Medicina, Fundação Universidade de Itaúna - UIT, Itaúna - MG, Brasil ${ }^{2}$ Médico Residente em Pediatria, Hospital Santa Casa de Barretos, Barretos - SP, Brasil

Endereço eletrônico: giovannamedina49@gmail.com
\end{abstract}

\section{RESUMO}

O sarampo é uma doença exantemática febril, altamente contagiosa e importante causa de morbimortalidade em crianças. Sua prevenção é garantida pela vacinação, disponível gratuitamente pelo Sistema Único de Saúde. Em 2016, o Brasil recebeu o certificado de eliminação da circulação do vírus, pela Organização Mundial da Saúde (OMS), corroborando a eficácia desse método. No entanto, mesmo com os avanços e os resultados comprovados, surtos podem se manifestar, principalmente se a cobertura vacinal não atingir 95\% da população, como no período entre 2014 a 2017, quando a taxa era de $84,97 \%$. Tem-se como objetivo desse estudo a análise crítica do surto de sarampo, os motivos da reemergência e propor possíveis intervenções. Assim, foi realizado uma revisão de literatura usando as bases de dados SciELO, MEDLINE e PubMed, entre 2018-2019, em português, buscando as causas da reemergência da doença. A hesitação vacinal é a recusa das vacinas ou atraso em aceitá-las. Segundo a OMS, esse fenômeno é influenciado pela falta de confiança na eficácia e segurança na vacina; complacência resultante da baixa percepção do risco de contrair a doença e conveniência da disponibilidade física ao acesso. Nesse contexto, o movimento anti-vacinas, tão antigo quanto a própria vacinação, é apontado como um dos dez maiores riscos à saúde. Na década de 1990, a tríplice viral foi associada ao autismo. Porém, mesmo após refutada, criou-se um estigma que ainda perdura e é disseminado pelo maior acesso à internet e meios de comunicação, onde também são expostos outros argumentos contra a vacina, a maioria sem embasamento científico. Além disso, a realidade sociodemográfica brasileira influencia a não imunização pelo difícil acesso às Unidades Básicas de Saúde, assim como pobreza e baixa escolaridade da população. Esses determinantes aumentam a susceptibilidade dos brasileiros à doença. Associado a isso, crises políticoeconômicas, principalmente na América Latina, contribuíram para a reemergência do sarampo nas fronteiras e a imigração promoveu a recirculação do vírus. Foram mais de 10 mil casos em 2018, concentrando-se no Norte, com disseminação para outras regiões. O surto atual de sarampo é multifatorial e necessita de intervenções que garantam cobertura vacinal adequada. Com isso, é essencial o incentivo ao uso de ferramentas digitais que verifiquem a veracidade da informação, diminuindo as "Fake News". Além disso, devem-se priorizar ações de prevenção coletiva, intensificando campanhas de vacinação, incluindo indivíduos provenientes de países endêmicos, já que esse método tem maior custo-efetividade no controle de doenças.

Palavras-chave: Sarampo, Surto, Vacina. 


\section{REFERÊNCIAS}

APS, L. R. de M. M. et al. Adverse events of vaccines and the consequences of nonvaccination: a critical review. Revista De Saúde Publica, v. 52, p. 40, 2018

BRANCO, V. G. C.; MORGADO, Flávio E. F. O Surto de Sarampo e a Situação Vacinal no Brasil. Revista de Medicina de Família e Saúde Mental, v. 1, n. 1, 2019

SATO, A. P. S. What is the importance of vaccine hesitancy in the drop of vaccination coverage in Brazil? Revista De Saude Publica, v. 52, p. 96, 2018 


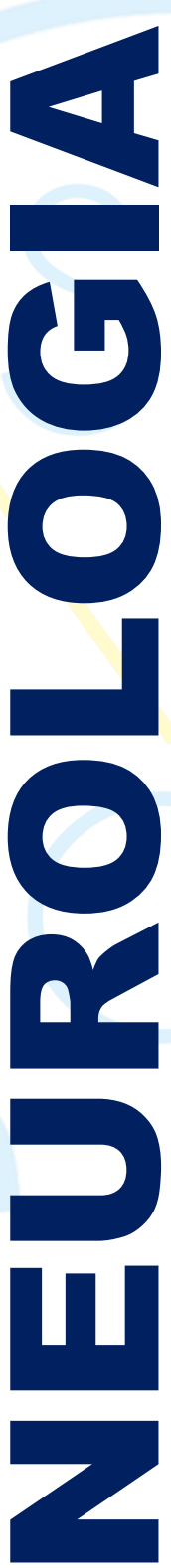




\title{
APRESENTAÇÃo CLÍNICA E DIAGNÓSTICO DA DEMÊNCIA VASCULAR NA POPULAÇÃO IDOSA
}

\author{
Matheus Baldini Camisão", Laura Coutinho Gonçalves ${ }^{1}$ Álvaro Camisão de Souza²
}

\author{
${ }^{1}$ Acadêmico de Medicina, Fundação Universidade de Itaúna - UIT, Itaúna - MG, Brasil \\ ${ }^{2}$ Médico Clínico, Unidade de Pronto Atendimento Padre Roberto, Divinópolis - MG, \\ Brasil \\ Endereço eletrônico: mbcamisao@gmail.com
}

\section{RESUMO}

A demência é uma síndrome clínica caracterizada por declínio cognitivo global e persistente, marcado por prejuízo de memória, distúrbios de linguagem, anormalidades viso-construtivas, agnosia e distúrbios no planejamento motor. A demência vascular (DV) é a demência decorrente de doença cerebrovascular. Segundo o Ministério da Saúde, a DV é a segunda causa mais comum de demência em idosos. Assim, com o aumento do número de idosos segundo projeções feitas pelo Instituto Brasileiro de Geografia e Estatística nos últimos anos, vê-se a necessidade do conhecimento de diagnóstico clínico para tratamento e melhoria da qualidade de vida dessa população. Dessa forma, essa revisão tem como objetivo verificar os principais fatores de risco relacionados à DV e à população idosa, além de revisar critérios diagnósticos. Para isso, foi feita uma revisão bibliográfica na base de dados SciELO e Biblioteca Virtual em Saúde, com os descritores demência, demência vascular, diagnóstico e idoso. Com a análise dos artigos obtidos, verificou que, a apresentação clínica da DV depende da causa e localização do infarto cerebral. As principais causas estão relacionadas com doenças crônicas presentes durante 0 processo de envelhecimento. Doença de grandes vasos leva comumente a múltiplos infartos corticais (com síndrome demencial cortical multifocal), enquanto uma doença de pequenos vasos, geralmente resultado de hipertensão arterial sistêmica (HAS) e diabetes melito, causa isquemia da substância branca periventricular e infartos lacunares (com demência subcortical, alterações frontais, disfunção executiva, comprometimento de memória, prejuízo atencional, alterações depressivas, lentificação motora, sintomas parkinsonianos, distúrbios urinários e paralisia pseudobulbar). Para diagnosticar demência vascular, é fundamental alinharmos a história clínica e o exame físico à avaliação neuropsicológica e aos exames de imagem. Existem atualmente, dois critérios desenvolvidos por instituições diferentes, NINDS-AIREN e CAD-DTC. Para ambos critérios, três aspectos são fundamentais: síndrome demencial, doença cerebrovascular e relação temporal razoável entre ambas. Na prática clínica, o escore isquêmico de Hachisnki também providencia elementos adicionais para o diagnóstico da DV. Portanto, o diagnóstico definitivo da maioria das síndromes demenciais depende do exame neuropatológico. Entretanto, uma avaliação clínica cuidadosa, incluindo anamnese detalhada, exames físico e neurológico, associado a determinações bioquímicas e de neuroimagem, podem possibilitar maior acurácia no diagnóstico diferencial. A diferenciação da DV baseiase em fatores clínicos: evidências de infartos cerebrais, um alto escore isquêmico de 
Hachinsnki e características clínicas da doença, como disfunção executiva precoce e perda de memória tardia.

Palavras-chave: Demência, Demência vascular, Manifestações neurológicas, Diagnóstico, Idoso.

\section{REFERÊNCIAS}

ANDRE, C. Demência vascular: dificuldades diagnósticas e tratamento. Arq. NeuroPsiquiatr., São Paulo, v. 56, n. 3A, p. 498-510, setembro. 1998. Disponível em: $<$ http://www.scielo.br/scielo.php?script=sci_arttext\&pid=S0004282X1998000300025 \&lng=en\&nrm=iso $>$. Acessado em: 04 nov. 2019

CRUZ, L.; TAVARES, A. Aspectos clínicos da demência vascular. Revista Médica de Minas Gerais, Belo Horizonte - MG, 13(2): 115-120, abr. - jun. 2003

GALLUCCI, J. N.; TAMELINI, Melissa G.; FORLENZA, Vicente, O. Diagnóstico diferencial das demências. Rev. psiquiatr. clín., São Paulo, v. 32, n. 3, p. 119-130, junho 2005. Disponível em: //www.scielo.br/scielo.php?script=sci_arttext\&pid=S010160832005000300004\&Ing=e n\&nrm=iso>. Acessado em: 03 nov. 2019 


\title{
DISTROFIA MUSCULAR DE CINTURAS DO TIPO 2B: RELATO DE CASO
}

\author{
José Abrantes Pêgo Neto¹, Bernardo Santos Resende¹, Caroline Mendonça Arruda1, Thaís \\ Andrade de Souza ${ }^{2}$
}

\begin{abstract}
${ }^{1}$ Acadêmico de Medicina, Fundação Universidade de Itaúna - UIT, Itaúna - MG, Brasil ${ }^{2}$ Médica Preceptora do Internato em Saúde Coletiva, Faculdade de Ecologia e Saúde Humana - FASEH, Vespasiano - MG, Brasil

Endereço eletrônico: netomed13@hotmail.com
\end{abstract}

\section{RESUMO}

A distrofia muscular de cinturas do tipo 2B (DMC2B) é uma doença neuromuscular genética, de herança autossômica recessiva, causada pela alteração na proteína disferlina, presente na membrana muscular. Dentre as distrofias musculares de cinturas-membros, a DMC2B é a segunda mais frequente em diversos países e o seu diagnóstico é desafiador na prática clínica. G.R.L., 43 anos, sexo feminino, iniciou aos 18 anos com dificuldade para correr e, aos 30 anos, para levantar-se e subir escadas. Aos 37 anos, houve progressão dos sintomas para os membros superiores. Além disso, queixa-se de mialgia e câimbras frequentemente. A paciente é filha de pais não consanguíneos e apresenta história familiar de duas irmãs com quadro clínico semelhante. Ao exame físico, a paciente possui fraqueza muscular com predomínio da musculatura distal dos membros inferiores e com envolvimento proximal nos quatro membros. Apresenta evidente atrofia de panturrilhas, hiporreflexia e marcha anserina. Os exames laboratoriais evidenciaram creatinofosfoquinase igual a 5130 e aldolase acima do valor de referência. A eletromiografia demonstrou padrão miopático, com predomínio da musculatura proximal nos quatro membros. A imunohistoquímica mostrou tecido muscular com ausência de expressão imunofenotípica da disferlina em fragmento do músculo bíceps braquial esquerdo. Na DMC2B, a fraqueza muscular é predominantemente proximal. No entanto, ao exame físico, observa-se o envolvimento da musculatura proximal e distal, ou seja, a sobreposição das características clínicas, o que dificulta o diagnóstico preciso do tipo de disferlinopatia. O início dos sintomas ocorre frequentemente na adolescência ou no início da vida adulta, sendo os membros superiores afetados tardiamente. Os níveis de creatinofosfoquinase podem estar aumentados cerca de 10 a 100 vezes do valor esperado, e a biópsia muscular pode produzir resultados falso-negativos. O exame de DNA, por meio de sequenciamento de nova geração, portanto, deve ser usado no diagnóstico genético de rotina, como a primeira abordagem de triagem, evitando exames mais invasivos, como a biópsia. A doença possui progressão lenta, com perda da marcha após a quarta década de vida. O diagnóstico da DMC2B tem se mostrado um desafio na prática clínica devido à sobreposição dos achados clínicos, a dificuldade na caracterização do padrão genético e a falta de achados laboratoriais específicos. As opções terapêuticas disponíveis não possuem finalidade curativa, o que confirma a necessidade de pesquisas na busca por abordagens que modifiquem a história natural da doença.

Palavras-chave: Distrofia muscular, Disferlina, Biópsia. 


\section{REFERÊNCIAS}

ANEQUINIA, I. P. et al. Disferlinopatias: revisão crítica para norteamento de abordagens terapêuticas. Cad. Pós-Grad. Distúrb. Desenvolv., São Paulo, v. 17, n. 2, p. 65-78, dez

$<$ http://pepsic.bvsalud.org/scielo.php?script

Disponível

em

03072017000200007\&lng=pt\&nrm=iso>.

Acesso

em 06

nov. 2019. http://dx.doi.org/10.5935/cadernosdisturbios.v17n2p65-78

COTTA, A. et al. Diagnóstico diferencial das distrofias musculares da cintura recessiva comum dos membros: por que e como? Arq. Neuro-Psiquiatr. São Paulo, v. 72, n. 9, p. 721-734, setembro de 2014. Disponível

em $<$ http://www.scielo.br/scielo.php?script=sci_arttext\&pid=S0004-

282X2014000900721\&lng=en\&nrm=iso>. Acesso

em

06 nov.

2019. http://dx.doi.org/10.1590/0004-282X20140110 


\title{
ESQUIZENCEFALIA BILATERAL DE LÁBIOS ABERTOS: UM RELATO DE CASO
}

\author{
Heitor Felipe Magalhães Menezes ${ }^{1}$, Thaís Andrade de Souza²
}

\author{
${ }^{1}$ Médico, Prefeitura de Itatiaiuçu, Itatiaiuçu - MG, Brasil \\ ${ }^{2}$ Médico Residente em Radiologia, Hospital Madre Teresa de Belo Horizonte, Belo \\ Horizonte - MG, Brasil \\ Endereço eletrônico: heitormenezesmed@gmail.com
}

\section{RESUMO}

A esquizencefalia é uma anomalia congênita do córtex cerebral, caracterizada por fendas que podem ser uni ou bilaterais e que atingem toda a espessura dos hemisférios cerebrais. Possui dois tipos de classificação: tipo I, definida pela presença de lábios fechados, ou seja, com as corticais justapostas; tipo II, definida pela presença de lábios abertos, em que a fenda se encontra preenchida por líquido cefalorraquidiano. Anteriormente era considerada uma anomalia rara, mas devido ao avanço dos métodos de imagem, o número de casos diagnosticados aumentou significativamente. Este trabalho tem como objetivo relatar o caso clínico de um paciente portador de esquizencefalia bilateral de lábios abertos. A.B.C., 10 anos, sexo feminino. Durante a gestação apresentou oligodrâmnio e imagem sugestiva de hidranencefalia ou holoprosencefalia semilobar. Nasceu de parto cesárea, idade gestacional de 37 semanas e 4 dias, peso de 2.465 gramas, perímetro cefálico de $30.5 \mathrm{~cm}$, com depressão cardiorrespiratória. Recebeu ventilação por pressão positiva na sala de parto com boa resposta e foi levada ao CTI. Após um dia, teve alta hospitalar e foi encaminhada para acompanhamento com a neurologia pediátrica ambulatorial. Aos 3 meses de idade realizou ressonância magnética do crânio e foi diagnosticada com esquizencefalia bilateral de lábios abertos, com ampla comunicação dos ventrículos laterais com o espaço subaracnóideo nas convexidades cerebrais. Paciente evoluiu com paralisia cerebral e atualmente, aos 10 anos, apresenta comprometimento grave da parte neuropsicomotora. A etiologia dessa anomalia permanece obscura, embora sejam descritos, como possíveis causas, fatores genéticos e ambientais. Já a gravidade do quadro clínico varia de acordo com a extensão e localização das lesões. Existem desde pacientes sem nenhum tipo de atraso no desenvolvimento intelectual até pacientes com os achados mais comuns, como epilepsia, déficit motor e comprometimento neurológico. Diferentemente do tipo $\mathrm{I}$, os quadros mais severos costumam estar associados ao tipo II. O padrão-ouro no diagnóstico da esquizencefalia é a ressonância magnética (RNM), por permitir melhor diferenciação entre a substância cinzenta e branca. A tomografia computadorizada também pode ser utilizada e possui vantagens sobre a RNM, como menor custo e maior acessibilidade. O diagnóstico precoce é fundamental para elaboração da proposta terapêutica dos pacientes, que varia conforme os graus de comprometimento neurológico. Além disso, a prevenção dessa anomalia é amplamente prejudicada pelo desconhecimento dos fatores etiológicos, o que corrobora com a necessidade de mais estudos científicos nesse campo.

Palavras-chave: Esquizencefalia, Anomalia congênita, Fendas cerebrais. 


\section{REFERÊNCIAS}

AMARAL, J. G. P. do et al. Esquizencefalia relato de onze casos. Arquivo de Neuropsiquiatria, 2001, 59(2-A):244-249

GRANATA, T. et al. Schizencephaly: clinical spectrum, epilepsy, and pathogenesis. Journal of Child Neurology 2005; 20:313-318

RODRIGUES, M. do C. de S. et al. Aspectos clínicos em 16 pacientes com diagnóstico tomográfico de esquizencefalia. Colégio Brasileiro de Radiologia e Diagnóstico por Imagem, 2006, 39(5):323-326 


\title{
MICROCEFALIA E DISTÚRBIOS PSICOMOTORES NA SÍNDROME DE AICARDI-GOUTIÈRES: UMA REVISÃO DE LITERATURA
}

\author{
Brenda Dias Ferreira', Rafael Ramos Corrêa Paulino', Patrícia Alves Maia Guidine²
}

${ }^{1}$ Acadêmico de Medicina, Fundação Universidade de Itaúna - UIT, Itaúna - MG, Brasil 2Docente Titular, Fundação Universidade de Itaúna - UIT, Itaúna - MG, Brasil Endereço eletrônico: brenda.dferreira98@gmail.com

\section{RESUMO}

A Síndrome de Aicardi-Goutières (SAG) é uma manifestação autossômica recessiva que interfere no desenvolvimento encefálico, causando distúrbios neuropsicomotores. Os achados clínicos consistem em atraso psicomotor, bem como microcefalia congênita ou adquirida. Ademais, exames complementares evidenciam calcificações encefálicas. Por se tratar de uma doença rara, a epidemiologia precisa é desconhecida. Entretanto, estimam-se aproximadamente 400 casos de SAG no mundo, sendo apenas 120 reportados na literatura. Propõe-se, portanto, conhecer os achados clínicos mais frequentes acerca da manifestação da doença e suas implicações na clínica médica. A revisão de literatura foi realizada na base de dados Biblioteca Virtual em Saúde, sendo selecionados artigos publicados entre os anos de 2009 e 2017, nas línguas inglesa e portuguesa, de acordo com os seguintes descritores: microcephaly, Aicardi-Goutières, calcificação. Segundo a literatura, crianças com SAG, que apresentaram microcefalia congênita, foram submetidas a exames de imagem complementares. A tomografia computadorizada revelou calcificação de áreas encefálicas em cem por cento dos pacientes. Dentre as regiões mais afetadas, estão o tálamo, globo pálido, putâmen e o núcleo denteado. Concomitantemente, imagens por ressonância magnética indicaram atrofia cerebral, em especial em relação ao córtex, comprometendo principalmente os lobos frontais e temporais. Em adição, os pacientes com quadro de microcefalia adquirida manifestaram desenvolvimento normal até cerca de seis meses de idade, quando, então, os primeiros sintomas psicomotores foram observados. A maioria dos pacientes apresentou elevados níveis de Interferon-alfa no líquor, um dos principais marcadores da SAG. Os núcleos da base, através das vias direta e indireta são primordiais na elaboração de programas motores, assim como são importantes na regulação de sistemas motores integrados no córtex. Desse modo, a calcificação de estruturas que os compõem tem como consequência a perda ou a deficiência de funções relacionadas à motricidade. No que se refere a anormalidades dos lobos frontal e temporal, as funções de fala e linguagem e habilidades motoras são prejudicadas, fato perceptível em grande parte dos pacientes que são incapacitados de se comunicar. Sugere-se ainda a indução de metabolismo de cálcio pelo Interferonalfa, que concorda com a ocorrência de calcificações e os níveis característicos da citocina. A compreensão da sintomatologia da SAG permite maior precisão do diagnóstico, ao se excluírem outras patologias neurológicas marcadas pela calcificação. Além disso, a abordagem de uma síndrome de baixa incidência se faz 
importante para promover a visibilidade das doenças raras, cujo atendimento universal e integral muitas vezes é negligenciado.

Palavras-chave: Calcificação fisiológica, Gânglios da base, Microcefalia.

\section{REFERÊNCIAS}

EYAID, W. et al. Intracranial calcifications, microcephaly, and seizure: If not congenital infection, what could it be? Neurosciences, v.17, n.3, p.248-252, maio. 2012

UGGETTI, C. et al. Aicardi-Goutières Syndrome: Neuroradiologic Findings and FollowUp. AJNR Am J Neuroradiol, v.30, p.1971-1976, dez. 2009 


\title{
SINTOMATOLOGIA E TRANSMISSÃO DA VARIANTE DA DOENÇA DE CREUTZFELDT - JACOB
}

\author{
Luísa Lima de Souza e Silva ${ }^{1}$, Ana Júlia Gonçalves Teixeira Silva ${ }^{1}$, Larissa Duarte Costa \\ Gomes ${ }^{1}$, Marcelo Eduardo de Lima Souza ${ }^{2}$
}

\begin{abstract}
${ }^{1}$ Acadêmico de Medicina, Fundação Universidade de Itaúna - UIT, Itaúna - MG, Brasil ${ }^{2}$ Médico Patologista Clínico, Hospital das Clínicas da Universidade Federal de Minas Gerais, Belo Horizonte - MG, Brasil

Endereço eletrônico: luisalimasouza@hotmail.com
\end{abstract}

\section{RESUMO}

A variante da Doença de Creutzfeldt-Jacob (vDCJ) é considerada uma Encefalopatia Espongiforme Transmissível (EET) subaguda, que provoca alterações no Sistema Nervoso Central (SNC). Caracteriza-se como um distúrbio neurodegenerativo raro, fatal e de rápida evolução, evidenciando a importância deste trabalho. Sua principal etiologia está relacionada à conversão conformacional da proteína príon celular ( $\mathrm{PrPc})$ para uma forma modificada, o príon PrPSc. Ainda, a vDCJ, descrita na década de 1990, está associada à transmissão alimentar devido ao consumo de carne e de subprodutos bovinos que desenvolveram a Encefalopatia Espongiforme Bovina (EEB). Destaca-se que o príon da vDCJ pode estar presente também nos tecidos periféricos e na corrente sanguínea, mesmo que em menores concentrações comparando-se ao SNC. Esse resumo objetiva apresentar a sintomatologia e a transmissão da vDCJ. A metodologia de busca consistiu-se em uma pesquisa de artigos científicos indexados nas bases de dados SciELO, BVS, NCBI e The Lancenet, em língua inglesa e portuguesa, publicados entre os anos de 2011 e 2018 . Em relação aos resultados encontrados e a discussão acerca desse assunto, a vDCJ apresenta os sintomas clínicos típicos de demência progressiva, acompanhada de anormalidades da função visual e do cerebelo, mioclonia, disfunção piramidal e extrapiramidal. Nessa neuropatologia, embora a maioria dos príons esteja depositada na membrana de células nervosas, há uma pequena concentração destes nos tecidos linfoides. Assim, os agentes das vDCJ replicam-se nestes locais, vão para a linfa e depois são conduzidos para o tecido sanguíneo. Dessa maneira, há relatos de níveis de príons no plasma durante a incubação e nas fases clínicas da doença. Em 2003, no Reino Unido, foi identificado o primeiro vínculo entre um doador de sangue, no período de incubação, e um receptor que posteriormente desenvolveu a vDCJ. Partindo de tais fatos, a vDCJ, apesar de rara, causa sérias implicações em relação à saúde neurológica do doente e de um futuro receptor sanguíneo de doador infectado, visto haver possibilidade de transmissão do agente por transfusão sanguínea. Diante disso, existe no Brasil certo rigor nas triagens clínicas de doadores de sangue, conforme regulamentação da Agência Nacional de Vigilância Sanitária (ANVISA) Portaria do Ministério da Saúde no 158, de 4-02-2016, artigo 59, que proíbe a doação de sangue de pessoas sob risco para a vDCJ. Isso se deve ao fato de não existir intervenções terapêuticas e profiláticas específicas disponíveis para doenças de príons, fazendo-se necessário, dessa maneira, o uso de eficientes ações preventivas. 
Palavras-chave: Dano encefálico crônico, Doadores de sangue, Encefalopatia Espongiforme Bovina, Príons.

\section{REFERÊNCIAS}

EDGEWORTH, J. A. et al. Detection of prion infection in variant Creutzfeldt-Jacob disease: a blood-based assay. The Lancet Articles, United States, v. 377, n. 9764, p. 487-493, fev. 2011

HOUSTON, F. et al. Creutzfeldt-Jakob disease and blood transfusion safety. The international Journal of Transfusion Medicine. London, v. 113, n. 3, p. 220-231, jan. 2018

PENNA, G. L. A. et al. Doença Creutzfeldt-Jakob: forma esporádica: relato de caso em pacientes de 81 anos. Rev Soc Bras Clin Med. Rio de Janeiro, v. 15, n. 3, p. 188191, mai. 2017 


\title{
USO DE CÉLULAS-TRONCO PLURIPOTENTES INDUZIDAS NO TRATAMENTO DA DOENÇA DE PARKINSON
}

\author{
Júlia Medeiros Tavares ${ }^{1}$, Débora do Amaral Teixeira²
}

\begin{abstract}
${ }^{1}$ Acadêmico de Medicina, Fundação Universidade de Itaúna - UIT, Itaúna - MG, Brasil ${ }^{2}$ Docente Titular, Fundação Universidade de Itaúna - UIT, Itaúna - MG, Brasil Endereço eletrônico: julia.m.tavares@hotmail.com
\end{abstract}

\section{RESUMO}

A doença de Parkinson (DP) constitui a segunda desordem neurodegenerativa crônica mais comum, sendo marcada pela perda de neurônios dopaminérgicos na região nigroestriatal, caracterizada, principalmente, por distúrbios motores, tremor em repouso, rigidez e bradicinesia. A terapia com reposição de dopamina tem efeitos satisfatórios na maioria dos pacientes, embora cause vários efeitos adversos, neuropsiquiátricos e autonômicos. Pesquisas demonstram que enxertos de células do mesencéfalo ventral fetal (FVM) possuem progenitores dopaminérgicos que podem proporcionar benefícios em longo prazo. Entretanto, questões éticas relacionadas a seu uso levaram à pesquisa de outra fonte de enxerto: as células-tronco pluripotentes induzidas (iPSCs) através da expressão forçada de fatores de pluripotência em células somáticas humanas adultas, o que traria resultados semelhantes e seria feita de maneira autóloga, contornando a necessidade de imunossupressão dos aloenxertos. Destarte, essa revisão busca analisar novas estratégias para o tratamento da Doença de Parkinson, visto a urgente necessidade de terapias adicionais à medicamentosa $\mathrm{e}$ por constituir um dos distúrbios neurodegenerativos mais frequente na população acima de 65 anos. Foi realizada uma revisão narrativa de artigos das plataformas PubMed e SciELO, indexados entre 2016 e 2019, dos quais foram selecionados seis artigos. Utilizou-se os seguintes descritores: "Parkinson", "Dopamina" e "Célulastronco". Constatou-se que o uso das iPSCs permite a realização de uma medicina personalizada, oferecendo terapias mais eficazes para a DP, por incorporar uma visão mais holística, considerando idade, estilo de vida, genótipo, personalidade e outras doenças concomitantes. Os neurônios dopaminérgicos são gerados a partir das iPSCs por exposição a fatores específicos que induzem a diferenciação neuronal e o padrão de mesencéfalo. As linhas iPSCs apresentam vantagens: (1) podem ser estabelecidas sem sacrifício de embriões humanos, necessário nos enxertos FVM, removendo grande obstáculo ético; (2) permitem combinações de antígeno leucocitário humano em tratamentos específicos do paciente, reduzindo a necessidade de imunossupressão; (3) resposta imune reduzida e maior sobrevida celular. Estudos em primatas mostram resultados motores significativos dois anos após o transplante, além de crescimento, proliferação e integração de redes neurais existentes. Nessa perspectiva, ressalta-se que os neurônios derivados de células-tronco têm potencial de fornecer soluções para dois dos principais problemas apresentados, a questão ética e a possibilidade de grande número de células, evitando os múltiplos cancelamentos de cirurgias devido à falta de tecido FVM. Assim, terapias celulares específicas do paciente, em combinação com a farmacogenética personalizada, 
podem oferecer o melhor caminho para mitigar a forma incapacitante de neurodegeneração da DP em humanos.

Palavras-chave: Parkinson, Células-tronco, Neurônios, Nigroestriatal, Dopamina.

\section{REFERÊNCIAS}

BARKER, R. A. Designing stem-cell-based dopamine cell replacement trials for Parkinson's disease. Nature Medicine, [s.I.], v. 25, n. 7, p.1045-1053, jul. 2019

CHEN, W. et al. Progress in dopaminergic cell-replacement and regenerative strategies for Parkinson's disease. Acs Chemical Neuroscience, Washington, Dc, p. $1-34,16$ out. 2018

STODDARD-BENNETT, T.; PERA, R. R. Treatment of Parkinson's Disease through Personalized Medicine and Induced Pluripotent Stem Cells. Cells, [s.I.], v. 8, n. 1, p.2635, 7 jan. 2019 


\title{
USO DO CANABIDIOL NO TRATAMENTO DA DOENÇA DE PARKINSON
}

\author{
Lara Amanda Silva Amaral ${ }^{1}$, Ana Luiza Oliveira Camisasca de Souza ${ }^{1}$, José Sérgio de \\ Carvalho Filho ${ }^{1}$, Mariana Silva Amaral', José Sérgio de Carvalho ${ }^{2}$
}

\begin{abstract}
${ }^{1}$ Acadêmico de Medicina, Fundação Universidade de Itaúna - UIT, Itaúna - MG, Brasil ${ }^{2}$ Médico, Prefeitura Municipal de São José do Goiabal, São José do Goiabal - MG, Brasil

Endereço eletrônico: lara.aamanda12102000@gmail.com
\end{abstract}

\section{RESUMO}

A doença de Parkinson (DP) é uma degeneração neural crônica, responsável por modificar as funções psicológicas e motoras do portador, tais como bradicinesia, tremor em repouso, rigidez e transtornos do humor. O tratamento convencional é realizado pela administração de precursores da dopamina. Entretanto, em muitos pacientes, o efeito diminui com o passar do tempo, além de causar reações graves. Sendo assim, é muito importante a procura por tratamentos alternativos que busquem uma maior eficácia e segurança a longo prazo. Estudos recentes mostram o benefício do uso terapêutico do fitocanabinóide canabidiol (CBD), um extrato da Cannabis sativa, visto que ele tem como alvo os gânglios da base, que são as regiões cerebrais envolvidas no processamento e execução dos movimentos corporais afetados pela doença de Parkinson. O presente trabalho trata-se de uma revisão bibliográfica, que busca avaliar a utilização do canabidiol para o tratamento da DP. Para isso, foram pesquisados textos publicados nas bases de dados MEDLINE e PubMed, utilizando as palavras-chave: "Doença de Parkinson", "tratamento", "canabidiol" e "parkinson's disease". Posteriormente, foram selecionados artigos a partir de 2004 em português e em inglês. Nos artigos foram relatados inúmeros estudos pré-clínicos envolvendo a administração do CBD em ratos e camundongos e, de forma geral, grande parte das pesquisas mostraram melhorias nos principais sintomas. Esses trabalhos sugerem que as propriedades potencialmente benéficas do CBD para o tratamento dessa patologia são consequências da provável atuação do canabidiol no sistema endógeno endocanabinoide, sendo esse um sistema formado por neurotransmissores lipídicos que se ligam a receptores canabinóides expressos no sistema nervoso central dos vertebrados. Essa atuação é explicada pelo fato de os compostos químicos presentes na Cannabis sativa serem semelhantes aos neurotransmissores do sistema. Sendo assim, os gânglios da base possuem receptores endocanabinoides CB1 e CB2 e o canabidiol age nesses locais, modulando as alterações neuroquímicas que são resultados da diminuição dos níveis de dopamina típicos do desenvolvimento da doença. A maioria dos estudos clínicos envolvendo a administração do CBD em pacientes com a DP, também mostraram resultados favoráveis na melhora dos sintomas, principalmente nos psicológicos, como o humor e o sono. Portanto, essa substância química tem um grande potencial para ajudar na melhora da qualidade de vida dos pacientes. Porém, por mais que os resultados sejam promissores, há necessidade de realizar mais estudos para evidenciar melhor os efeitos do CBD a 
longo prazo. Sendo assim, os resultados obtidos ainda não são suficientes para indicá-lo para pacientes.

Palavras-chave: Doença de Parkinson, Canabidiol, Tratamento.

\section{REFERÊNCIAS}

BASSI, M. S. et al. Cannabinoids in Parkinson's Disease. Cannabis Cannabinoid Res., [S. I.], ano 2017, v. 2, n. 1, p. 21-29, 1 fev. 2017

FERNÁNDEZ-RUIZ, J. et al. Prospects for cannabinoid therapies in basal ganglia disorders. British Journal of Pharmacology, [S. I.], v. 163, n. 7, p. 1365-1378, 1 ago. 2011

SANTOS, R., HALLAK, J., \& CRIPPA, J. A. O uso do canabidiol (CBD) no tratamento da doença de Parkinson e suas comorbidades. Revista De Medicina, (2019) 98(1), 46-51. https://doi.org/10.11606/issn.1679-9836.v98i1p46-52 


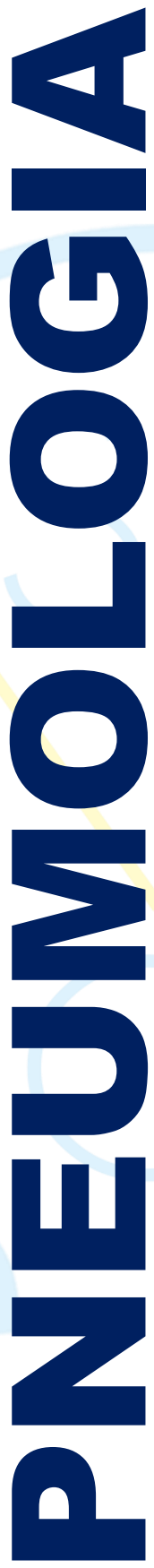




\title{
E-CIGARETTES: AVANÇO OU RETROCESSO NA SAÚDE PÚBLICA?
}

\author{
Natália Mourão Feio de Freitas ${ }^{1}$, André Luís Campos Louredo Pereira1 ${ }^{1}$, Wagnélia Guimarães \\ Pereira ${ }^{1}$, Olber Moreira de Faria²

\begin{abstract}
${ }^{1}$ Acadêmico de Medicina, Fundação Universidade de Itaúna - UIT, Itaúna - MG, Brasil ${ }^{2}$ Docente Titular, Fundação Universidade de Itaúna - UIT, Itaúna - MG, Brasil Endereço eletrônico: natimourao@icloud.com
\end{abstract}

\section{RESUMO}

Os e-cigarettes são dispositivos que, ao serem aquecidos, liberam vapor líquido contendo nicotina, flavorizantes, propilenoglicol e/ou glicerol, além de outros aditivos, colocados no mercado como alternativa aos cigarros convencionais e como meio de interromper esse hábito. Embora proscrito no Brasil, seu uso tem crescido em níveis alarmantes nos últimos anos devido a propagandas exibicionistas que ameaçam décadas de campanhas de saúde pública bem-sucedidas que desmistificaram o tabagismo. Em consonância com esse aumento, uma série de casos têm sido registrados de pacientes com dificuldade respiratória aguda e grave após uso de tais produtos. Além disso, o padrão de uso duplo de cigarro eletrônico e convencional, que é o mais comum, está associado a aumento da dependência à nicotina. Esse trabalho objetiva demonstrar os riscos da popularização dos e-cigarettes para a saúde, bem como desencorajar seu uso, evitando possíveis repercussões devastadoras. Foi realizada uma revisão narrativa de artigos científicos internacionais usando a plataforma PubMed e site da revista New England Journal of Medicine. Foi demonstrado que os fluidos presentes nos e-cigaretttes contém, pelo menos, seis grupos de componentes potencialmente tóxicos, rastros de metais pesados, endotoxinas bacterianas e glucanos fúngicos. O propilenoglicol, quando vaporizado, pode formar o óxido de propileno, carcinógeno classe 2B pela International Agency for Research on Cancer, enquanto o glicerol forma acroleína, que pode causar irritação do trato respiratório superior. Há, entretanto, grande variabilidade na exposição a esses constituintes dos aerossóis entre os usuários, a depender dos dispositivos, dos e-liquids e dos modos de uso. De acordo com o tipo de agente químico e quantidade de material inalado, pacientes podem apresentar sintomas, desde desconforto respiratório, à injúria aguda às vias aéreas, dano ao parênquima com pneumonite, edema alveolar, parada respiratória e morte. Estudo reportou 53 casos nos Estados Unidos de pacientes apresentando desconforto respiratório agudo grave após uso de e-cigarettes. Na revisão de literatura evidencia-se que, inicialmente concebidos como solução para o problema de saúde pública do tabaco, os e-cigarettes acabaram se tornando uma epidemia que urge por uma intervenção, pois apesar de serem necessárias maiores investigações para determinar quais os agentes diretamente envolvidos na patogenia, existe uma clara associação com seu uso. Portanto, o uso desses dispositivos deve ser desencorajado pela comunidade médica e políticas intervencionistas devem ser traçadas para evitar futura sobrecarga do sistema de saúde terciário com os efeitos nocivos dessa prática. 
Palavras-chave: Sistemas eletrônicos de liberação de nicotina, Saúde pública, Tabagismo, Patogênese, Síndrome do Desconforto Respiratório do Adulto.

\section{REFERÊNCIAS}

LAYDEN, J. E, et al. Pulmonary illness related to e-cigarette use in illinois and wisconsin-preliminary report. N Engl J Med. 2019 Sep 6. Disponível em <DOI: 10.1056/NEJMoa1911614>

ORELLANA-BARRIOS, M. A; PAYNE, D; MULKEY, Z. et al. Electronic cigarettes - a narrative review for clinicians. Am J Med. 2015; 128(7): 674-681. Disponível em <DOI: 10.1016/j.amjmed.2015.01.033>

FAIRCHILD, A. L., BAYER, R. \& COLGROVE, J. The renormalization of smoking? Ecigarettes and the tobacco "endgame". N Engl J Med 2014; 370, 293-295. Disponível em <DOI: 10.1056/NEJMp1313940> 


\title{
O USO DO CIGARRO ELETRÔNICO: DO CONTROLE DO TABAGISMO AO RISCO DE SAÚDE
}

\author{
Fernanda Luiza Gomes de Abreu¹, Andrea Lisboa Barbosa¹, Giovanna Luiza Medina \\ Ferreira1, Gustavo Mendes Santiago1, Mariana Márcia Marçal Vasconcelos Reis²
}

\author{
${ }^{1}$ Acadêmico de Medicina, Fundação Universidade de Itaúna - UIT, Itaúna - MG, Brasil \\ 2Médica Residente em Pneumologia, Santa Casa de Misericórdia de Belo Horizonte, \\ Belo Horizonte - MG, Brasil \\ Endereço eletrônico: fernandaluizaabreu17@gmail.com
}

\section{RESUMO}

O tabagismo é um importante problema de saúde pública mundial, sendo uma das principais causas de doenças e mortes evitáveis. Tendo em vista os efeitos deletérios do uso do cigarro, foram desenvolvidos produtos derivados do tabaco que são usados como substitutos do cigarro convencional, dentre eles os cigarros eletrônicos (CE). Estes dispositivos são vaporizadores eletrônicos alimentados por bateria, que supostamente fornecem baixas doses de nicotina e outros aditivos em aerossol. Porém, existem controvérsias sobre sua eficácia e inocuidade, sendo proibida a comercialização de CE em 2009 pela Agência Nacional de Vigilância. Mesmo assim, há uma crescente popularização do uso no Brasil, principalmente entre os jovens. Tem-se como objetivo desse estudo a análise crítica sobre consumo dos CE, seus riscos à saúde e efeitos no controle do tabagismo. Assim, foi realizado uma revisão de artigos nas bases de dados SciELO, Cochrane e PubMed, dos últimos 5 anos, em inglês e português, evidenciando os benefícios e riscos da utilização dos CE no controle do tabagismo. Os CE são anunciados como produtos com doses menores de nicotina e substâncias tóxicas comparados aos cigarros tradicionais. Entretanto, os níveis desses compostos podem variar e não corresponder a concentração descrita, além de possuir aditivos carcinogênicos. Os principais produtos são a glicerina e propilenoglicol, que podem causar irritação do trato respiratório, tosse, obstrução das vias aéreas, dor torácica e acometimento do sistema nervoso central e imunológico. Recentemente, pacientes jovens, previamente hígidos, apresentaram dispneia progressiva, fadiga, hipoxemia, vômito, diarreia, dor abdominal e histórico de uso de cigarros eletrônicos nas semanas antes do início dos sintomas. Líquidos contendo nicotina têm sido associados a uma variedade de apresentações de doenças, como pneumonite química, pneumonia eosinofílica, pneumonite de hipersensibilidade aguda, pneumonia lipoide, lesão pulmonar aguda e Síndrome do desconforto respiratório agudo. Segundo New England Journal of Medicine, durante o período 2017-2018, a prevalência do uso de CE aumentou 9\% entre os estudantes do ensino médio. Essa prática compromete o progresso das ações de prevenção ao tabagismo e promoção de estilo de vida livre do consumo. Os CE foram inicialmente criados como substitutos supostamente seguros dos cigarros convencionais, mas até o momento, não há comprovação cientifica sobre sua eficácia e consequências a longo prazo. Os recentes relatos de acometimento pulmonar grave reforçam a necessidade de novos estudos, fiscalização e regulamentação sobre seu uso.

Palavras-chave: Cigarros eletrônicos, Vaping, E-cigarettes, Vapers. 


\section{REFERÊNCIAS}

KNORST, M. M. et al. Cigarro eletrônico: o novo cigarro do século 21? Programa de Pós Graduação em Ciências Pneumológicas, Universidade Federal do Rio Grande do Sul, e no Hospital de Clínicas de Porto Alegre. J Bras Pneumol Porto Alegre (RS), Brasil. 2014;40(5): 564-573

MARTINS, S. R. Cigarros eletrônicos: o que sabemos? Estudo sobre a composição do vapor e danos à saúde, o papel na redução de danos e no tratamento da dependência de nicotina. Instituto Nacional de Câncer José Alencar Gomes da Silva. - Rio de Janeiro: INCA, 2016

SILVA, A. L.O. da; MOREIRA, J. C. A proibição dos cigarros eletrônicos no Brasil: sucesso ou fracasso? Ciênc. Saúde coletiva, Rio de Janeiro, v. 24, n. 8, p. 30133024, ago. 2019 


\title{
TUBERSULOSE PLEURAL: A IMPORTÂNCIA DOS EXAMES COMPLEMENTARES PARA O DIAGNÓSTICO
}

\author{
Luiza Pires Miranda1', Rômullo Vinícius Dutra Menezes ${ }^{1}$, Michelle Andreata Souza Moura²
}

${ }^{1}$ Acadêmico de Medicina, Fundação Universidade de Itaúna - UIT, Itaúna - MG, Brasil ${ }^{2}$ Médico Residente, Santa Casa de Misericórdia de Belo Horizonte, Belo Horizonte MG, Brasil

Endereço eletrônico: lupimiranda09@hotmail.com

\section{RESUMO}

A Tuberculose Pleural (TB Pleural) é uma forma de tuberculose extrapulmonar que cursa com derrame pleural após a ruptura do foco caseoso subpleural para o espaço pleural ${ }^{1}$. Pode cursar com febre, dor torácica, tosse predominantemente seca e diferentes graus de dispneia, sempre na dependência do volume do derrame pleural. Este, geralmente, é unilateral, de pequena a moderada intensidade, predominando em adultos jovens ${ }^{2}$. O diagnóstico definitivo é feito pela biópsia pleural e pela dosagem da adenosina (ADA). Estima-se que, em todo o mundo, cerca de nove milhões de pessoas desenvolvem tuberculose a cada ano. Aproximadamente $80 \%$ delas vivem em 22 países diferentes, sendo que o Brasil ocupa o 15 lugar, com cerca de 80 mil casos notificados a cada $\mathrm{ano}^{3}$. Diante disso, este trabalho objetiva relatar um caso de TB pleural. Paciente masculino, 53 anos, foi levado à UPA com queixa de dispneia progressiva paroxística noturna há 2 semanas, dor em hipocôndrio direito e em base do hemitórax direito associada à movimentação. Negava febre e perda ponderal. Apresentava, no entanto, D-dímero superior a 3 mil e dessaturação, mesmo em repouso. Inicialmente, o paciente foi submetido a angiotomografia de tórax, devido à suspeita clínica de tromboembolismo pulmonar (TEP). No entanto, o exame descartou TEP, evidenciando derrame pleural moderado, com sinais de pleurite crônica, sugestivo de TB Pleural. Assim sendo, o paciente foi avaliado pela equipe de cirurgia torácica, que realizou a drenagem pleural, além de biópsia de lesão granulomatosa. O anátomo patológico revelou granuloma caseoso e houve grande aumento do ADA, confirmando o diagnóstico de tuberculose pleural. Diante disso, foi iniciado o esquema RIPE (rifampicina + isoniazida + pirazinamida + etambutol) para tratamento da patologia. Com isso, apesar da clínica pouco favorável ao diagnóstico de tuberculose pleural, os exames complementares foram de grande importância para 0 esclarecimento do caso. Portanto, o achado de necrose caseosa em processo granulomatoso, é patognomônico de tuberculose, sendo o indicativo principal para iniciar o tratamento dessa doença, que ainda pode ser letal.

Palavras-chave: Pleurisia tuberculosa, Tuberculosis. 


\section{REFERÊNCIAS}

CAPONE, D. et al. Tuberculose extrapulmonar. Revista Hospital Universitário Pedro Ernesto, [S. I.], p. 1-17, 6 set. 2018. Disponível em: https://www.epublicacoes.uerj.br/index.php/revistahupe/article/view/9210/7093. Acesso em: 1 out. 2019

BETHLEM, E. P. Manifestações Clínicas da Tuberculose Pleural, Ganglionar, Geniturinária e do Sistema Nervoso Central. Pulmão RJ, [S. I.], p. 19-22, 21 jan. 2012. Disponível em: http://www.sopterj.com.br/wpcontent/themes/_sopterj_redesign_2017/_revista/2012/n_01/05.pdf. Acesso em: 1 out. 2019

SEISCENTO, M. et al. Tuberculose pleural: Tuberculous pleural effusions. Jornal Brasileiro de Pneumologia, [S. I.], p. 1806-3756, 6 ago. 2006. Disponível em: http://www.scielo.br/scielo.php?script=sci_arttext\&pid=S1806-37132006000900003.

Acesso em: 4 out. 2019 


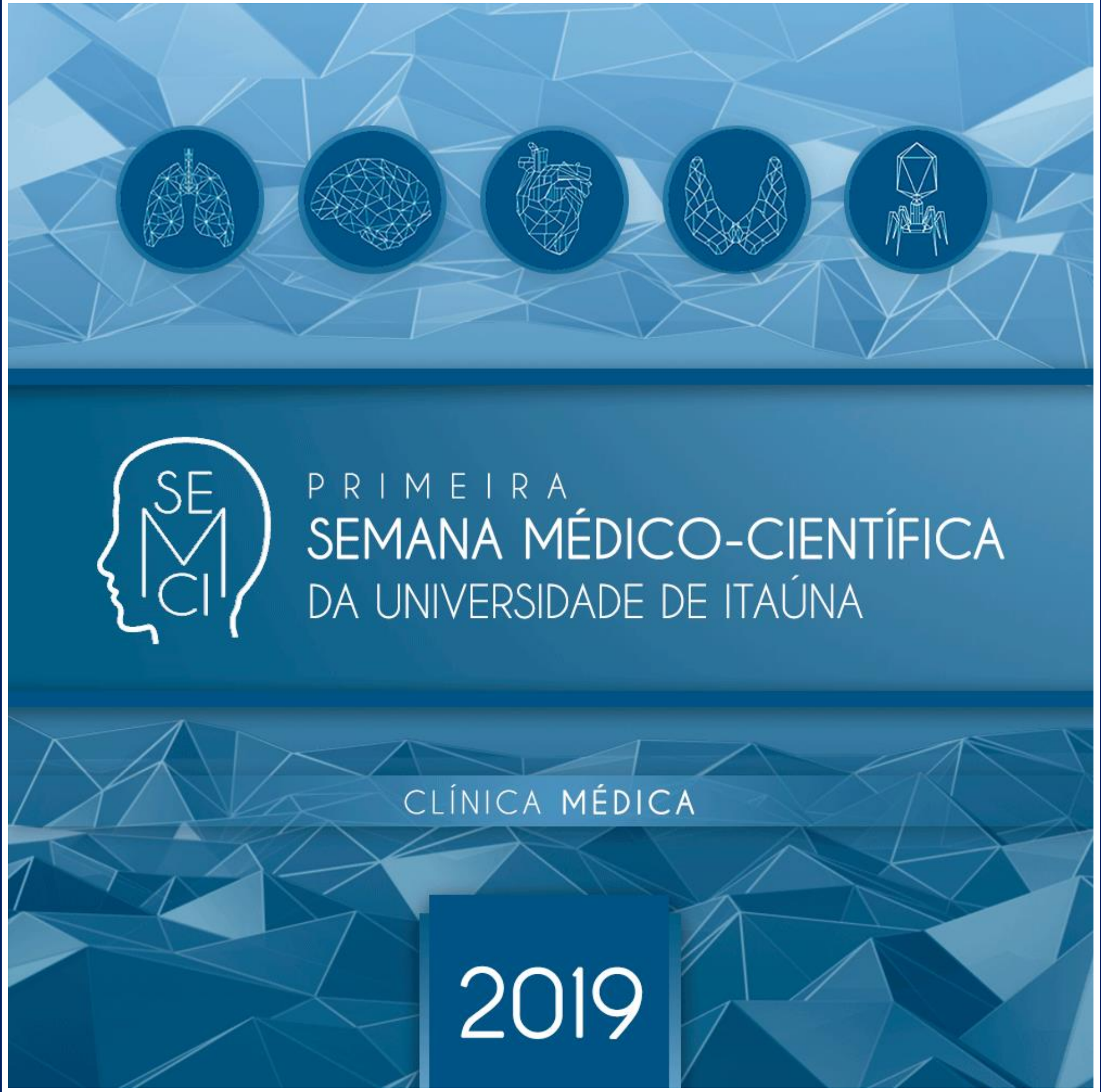

